University of Nebraska - Lincoln

DigitalCommons@University of Nebraska - Lincoln

USDA National Wildlife Research Center - Staff Publications
U.S. Department of Agriculture: Animal and Plant Health Inspection Service

June 2006

\title{
Modelling wildlife rabies: Transmission, economics, and Conservation
}

\author{
Ray T. Sterner \\ US Department of Agriculture, Animal and Plant Health Inspection Service,Wildlife Services, \\ NationalWildlife Research Center \\ Graham C. Smith \\ Central Science Laboratory, Sand Hutton, York, YO41 1LZ, UK
}

Follow this and additional works at: https://digitalcommons.unl.edu/icwdm_usdanwrc

Part of the Environmental Sciences Commons

Sterner, Ray T. and Smith, Graham C., "Modelling wildlife rabies: Transmission, economics, and Conservation" (2006). USDA National Wildlife Research Center - Staff Publications. 446.

https://digitalcommons.unl.edu/icwdm_usdanwrc/446

This Article is brought to you for free and open access by the U.S. Department of Agriculture: Animal and Plant Health Inspection Service at DigitalCommons@University of Nebraska - Lincoln. It has been accepted for inclusion in USDA National Wildlife Research Center - Staff Publications by an authorized administrator of DigitalCommons@University of Nebraska - Lincoln. 


\title{
Review
}

\section{Modelling wildlife rabies: Transmission, economics, and conservation}

\author{
Ray T. Sterner ${ }^{a, *}$, Graham C. Smith ${ }^{b}$ \\ ${ }^{a}$ US Department of Agriculture, Animal and Plant Health Inspection Service, Wildlife Services, National Wildlife Research Center, Fort Collins, \\ CO, USA \\ ${ }^{\mathrm{b}}$ Central Science Laboratory, Sand Hutton, York, YO41 1LZ, UK
}

\section{A R T I C L E I N F O}

Available online 6 June 2006

Keywords:

Benefit-cost analysis

Conservation

Disease

Economics

Models

Rabies

Vaccination

Wildlife

\begin{abstract}
A B S T R A C T
Rabies is a fatal zoonotic disease of mammals; it exacerbates the uncertainty of conserving populations of some threatened mammals (TM). Modelling affords an inexpensive, a priori way of studying key parameters of wildlife rabies transmission, rabies management economics, and TM conservation. Numerous models of rabies transmission have been published. Linear density dependent models predicted that a threshold density $\left(K_{T} \leqslant 1.0\right)$, possibly attained by culling or contraception, would eliminate an epizootic through reduced contacts among host animals. Density independent models predicted less advantage of culling and contraception in rabies control due to limited contacts among territorial host animals. Recent stochastic, mixed models offer novel predictions about the role of culling, fertility control, and oral rabies vaccination (ORV) in disease management. Use of a "threshold successful contact" rate $\left(C_{T}\right)$ as a parameter in these models predicts that density reduction of host animals will enhance ORV campaigns in non-TM contexts via more efficient bait delivery and vaccination. Economic analyses of medical, public health, and veterinary costs have shown post-exposure prophylaxis (PEP) and increased pet vaccinations (PV) to be major rabies-caused expenses during and after epizootics in North America. No modelling efforts have examined either the benefits-costs of rabies management strategies to conserve TM or the use of ORV, per se, to conserve TM - an omission due in part to the lack of methodologies for properly valuing TM (potential savings) and the expense or lower priority of using ORV for TM protection. This paper: (1) describes key aspects of rabies-transmission models in wildlife, (2) posits the use of $C_{T}$ to predict disease persistence, (3) reviews selected ORV strategies, economic studies, and benefit-cost models associated with the use of ORV as a means of rabies control in non-TM situations, (4) discusses implications of these models to the conservation of TM, and (5) recommends five steps to improve modelling of rabies transmission (wildlife disease in general), rabies-control economics, and TM conservation.
\end{abstract}

(c) 2006 Elsevier Ltd. All rights reserved.

\footnotetext{
* Corresponding author: Tel.: +1970 266 6170; fax: +1970 2666157.

E-mail address: ray.t.sterner@aphis.usda.gov (R.T. Sterner).

0006-3207/\$ - see front matter @ 2006 Elsevier Ltd. All rights reserved.

doi:10.1016/j.biocon.2006.05.004
} 


\section{Contents}

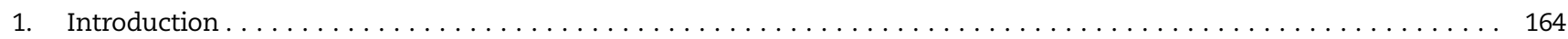

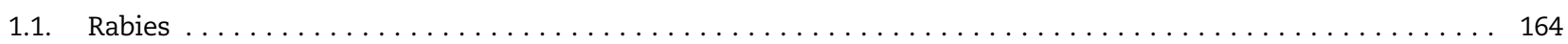

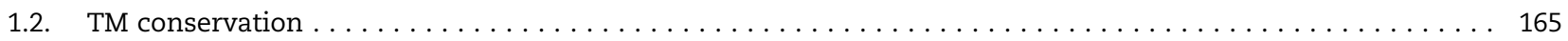

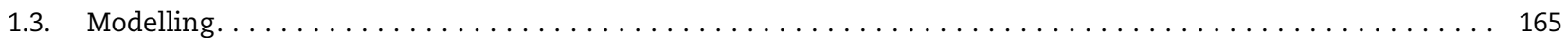

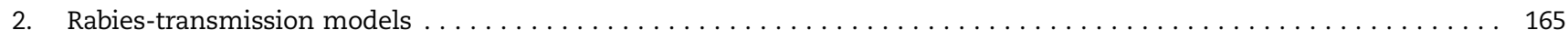

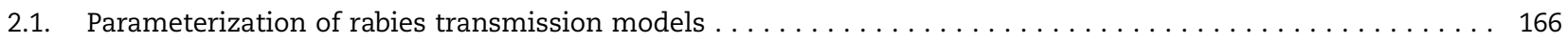

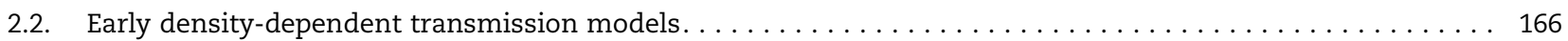

2.3. Early density-independent transmission models $\ldots \ldots \ldots \ldots \ldots \ldots \ldots \ldots \ldots \ldots \ldots \ldots$

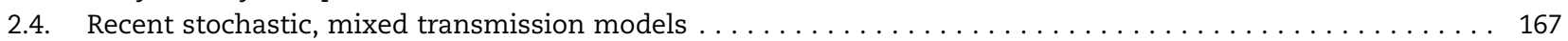

2.5. Implications of transmission models to rabies management with non-TM $\ldots \ldots \ldots \ldots$

2.6. Implications of transmission models to rabies management with $\mathrm{TM} \ldots \ldots \ldots \ldots$

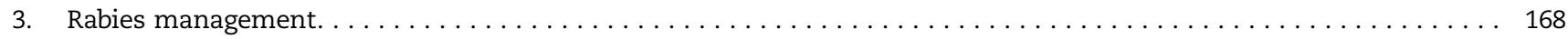

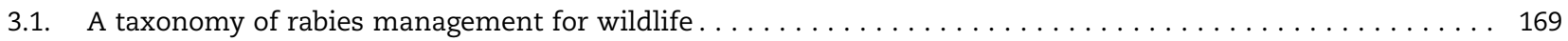

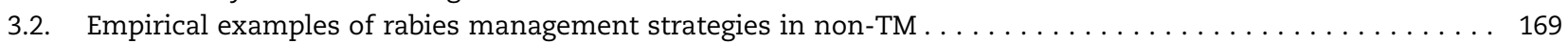

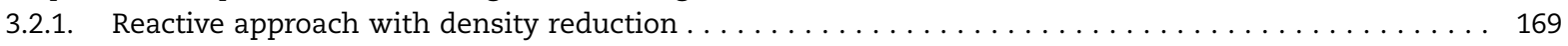

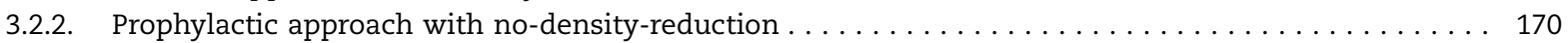

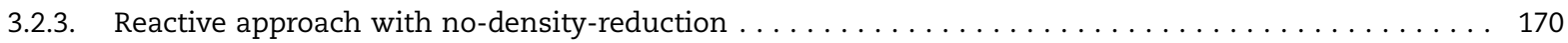

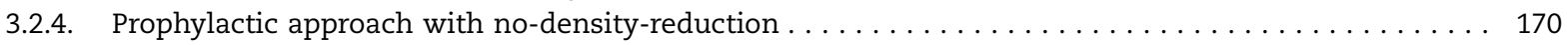

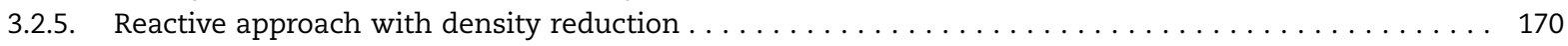

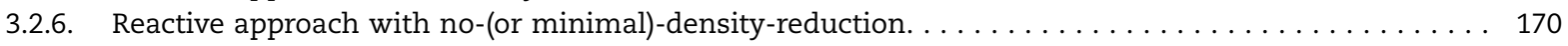

3.2.7. Reactive approach with combined density reduction and no-density-reduction. . . . . . . . . . 171

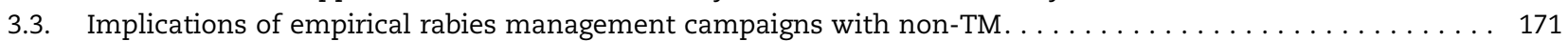

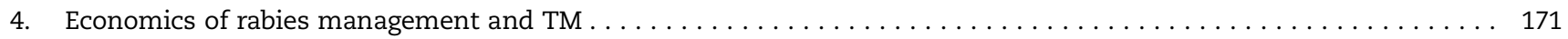

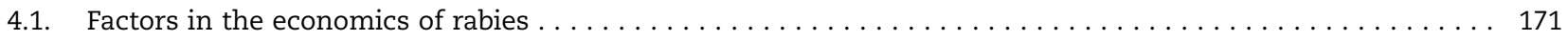

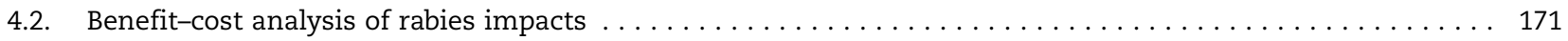

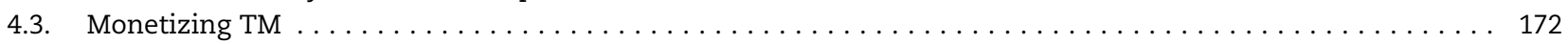

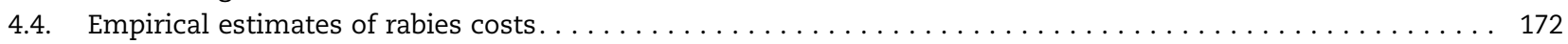

4.5. Potential costs and savings of rabies management involving ORV for non-TM $\ldots \ldots \ldots \ldots$

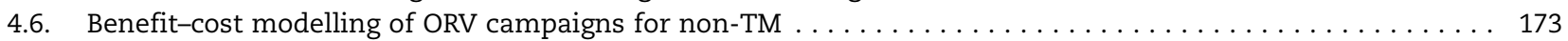

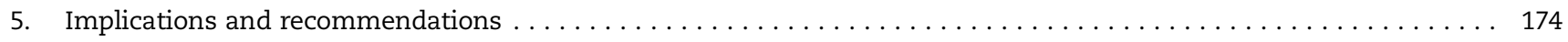

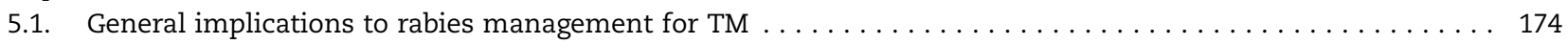

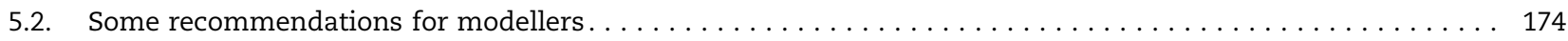

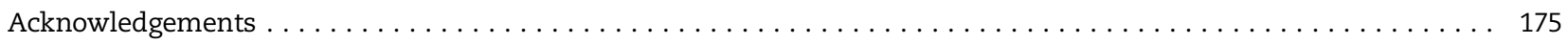

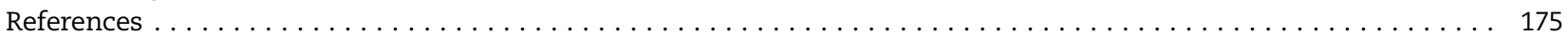

\section{Introduction}

Rabies is an acute, viral encephalomyelitis unique to mammals (Niezgoda et al., 2002). This disease remains an important human health and wildlife management concern worldwide (Meslin et al., 1994; Meltzer and Rupprecht, 1998a,b). The presence of rabies in an area exacerbates the uncertainty of conserving rare and threatened mammals (TM). Modelling offers a relatively inexpensive, a priori way to examine salient parameters of wildlife rabies transmission, rabies management economics, and rabies impacts on TM conservation.

Here, we: (1) describe key aspects of rabies-transmission models in wildlife, (2) posit the use of a threshold successful contact rate $\left(C_{\mathrm{T}}\right)$ to predict disease persistence, (3) present a review of economic studies and recent benefit-cost models associated with the use of oral rabies vaccination (ORV) as a means of rabies (disease) management, (4) discuss the implications of these models and literature to the conservation of TM, and (5) present a 5-step approach to improved modelling of rabies (or wildlife disease in general), the economics of rabies management, and the conservation of TM in rabies endemic areas.

\subsection{Rabies}

Rabies is a Lyssavirus in the family Rhabdoviridae (Wunner, 2002; Brookes et al., 2004). Antigenic and genetic typing of lyssaviruses currently has delineated seven sub-types: classic rabies virus (RABV), Australian bat lyssavirus (ABLV), Duvenhage virus (DUVV), European bat lyssavirus 1 (EBLV-1), European bat lyssavirus 2 (EBLV-2), Mokola virus (MOKV), and Lagos bat virus (LBV) (Smith, 2002b). Rabies still causes thousands of human deaths annually in parts of India and Africa, where effective public health and pet vaccination programs have not been implemented (Meslin et al., 1994; Meltzer and Rupprecht, 1998a).

Rabies (RABV) is present throughout every continent except Antarctica (Smith, 2002b). In Europe, the red fox (Vulpes vulpes), raccoon dog (Nyctereutes procyonoides), and potentially the Eurasian badger (Meles meles) are reservoirs of terrestrial wildlife rabies (Macdonald, 1980; Smith, 2002a,b). In North America, the raccoon (Procyon lotor), arctic fox (Alopex lagopus), red fox, gray fox (Urocyon cinereoargenteus), skunk (Mephitis mephitis, Spilogale putoris), and various insectivorous bats (e.g., Myotis spp., Eptesicus spp., Lasionycterus spp.) are reser- 
voirs of different strains of RABV (Nadin-Davis et al., 2001; Krebs et al., 2003; Smith, 2002b). Domestic dogs (Canis familiaris), insectivorous bats, and vampire bats (Desmodus rotundus) are the major reservoirs in South America (Schaefer et al., 2005; Smith, 2002b). In Africa and Asia, domestic dogs are a main reservoir, with more research needed to identify wildlife reservoirs (Smith, 2002b; Randall et al., 2006). Most modelling research has dealt with RABV.

Other Lyssaviruses occur in Europe, where primary reservoirs of EBLV-1 and EBLV-2 are insectivorous bats, in Australia, where ABLV has been recorded in insectivorous and fruit bats (megachiroptera), in Asia, where ABLV and new variants have been recorded in insectivorous and fruit bats, and in Africa, where reservoir species for DUVV, LBV, MOKV are unknown (Smith, 2002b; Cliquet and Picard-Meyer, 2004; Kuzmin et al., 2005).

"Spillover" infections refer to the transmission of rabies to a species that is not a natural reservoir of the disease (Fig. 1). These occur as a result of interspecies contacts, usually involve relatively few animals, and often end quickly as rabid animals succumb (Niezgoda et al., 2002). One exception to this occurred in the US recently when a strain of bat rabies appeared to mutate and continue to infect skunks (see Engeman et al., 2003a; Slate et al., 2005).

\subsection{TM conservation}

In $2004, \approx 1101$ species of mammals were identified as at risk of extinction worldwide (International Union for Conservation of Nature and Natural Resources, 2006). This count of TM was based on $4853(20 \%)$ and $5416(23 \%)$ of the species evaluated and described, respectively, as critically endangered, endangered, and vulnerable (International Union for Conservation of Nature and Natural Resources, 2006).

Rabies poses greater or lesser risks to certain species or populations of TM. While any species of wild or domestic mammal can contract rabies from an infected animal (i.e., bite, exposure to saliva, respiratory particles), a continuum of species susceptibility is evident in rabies infections. A hierarchy exits from most to least susceptible mammals - bats, canids (Canidae spp.), and cats (Felidae spp.) to meso-carnivores (e.g., raccoons, skunks), primates (e.g., Cebidae spp., Homindae spp.), and ungulates (e.g., Alces spp., Cervus spp.) to rodents (Rodentia spp.), lagomorphs (e.g., Lepus spp., Sylvivagus spp.), shrews (Sorex spp.), and marine mammals (e.g., Pusa hispida) (Niezgoda et al., 2002).

Despite recent gains in understanding the epidemiology and pathogenesis of rabies afforded by molecular genetic typing, much about the reservoir-host cycle and the occurrence of new variants remains unknown (Parker and Wilsnack, 1966; Charlton and Casey, 1979; Aubert et al., 1991; Badrane and Tordo, 2001; Smith, 2002b; Slate et al., 2005). Species of bats probably represent the most widespread and difficult to manage reservoirs - no ORV baits for bats are available (Johnston and Tinline, 2002). Blanford's fox (Vulpes cana), Ethiopian wolf (Canis simensi), and African wild dogs (Lycaon pictus) are well-cited examples of TM at risk of potential spillover infections from domestic dogs and wildlife hosts (e.g. Macdonald, 1993; Randall et al., 2004; Randall et al., 2006).

\subsection{Modelling}

Models are symbolic (mathematical) expressions of natural phenomena and can entail numerous sub-types dependent upon methodology (Burnham and Anderson, 2002). Assignment of parameters is the defining step of modelling (Smith, 2001; Burnham and Anderson, 2002). Parameters refer to attributes of phenomena that cause or correlate with outputs. Variables are specific values of parameters that can be substituted into a model to assess computational predictions. Between two and five parameters comprise most models (Smith, 2001; Burnham and Anderson, 2002).

Modelling encompasses simple to complex expressions. It affords a unique tack in the study of disease, economics, and conservation. Typically, assumptions are stated, independent variables are quantified, and iterative projections of the model are obtained, with sensitivity analysis (or other uncertainty reduction technique) used to assess how changes in a quantified variable reduce or limit the uncertainty of outcomes (Zerbe and Dively, 1994; Meltzer, 1996; Burnham and Anderson, 2002). The predictions, inferences, and explanations gained in managing rabies, deriving the benefits-costs of rabies management, and projecting TM survivability in rabies endemic areas will determine the effectiveness of conceived models.

Uncertainty characterizes modelling (Zerbe and Dively, 1994; Burnham and Anderson, 2002). This is a result of unknown or poorly specified biological (e.g., population density, age-class structure, target animal acceptance, intra/interspecies transmission), economic (e.g., direct, indirect, induced, and intangible costs/savings), and conservation inputs (e.g., spatial separation of TM, species-specific behaviours of TM) to mathematical expressions (Zerbe and Dively, 1994; Burnham and Anderson, 2002).

Reducing uncertainty is a goal of modelling (Burnham and Anderson, 2002). Statistical confidence limits offer an analogy. These limits are based upon the variance evident within samples. Estimates of means for samples of size $n$ can then be used to specify the range (limits) of means that will probably occur in future samples (Cochran and Cox, 1957). Similar to confidence limits, modelling must quantify the uncertainty in the outputs of an expression. This can be done by using realistic scenarios (e.g., best-/worst-case) or other techniques (e.g., Monte Carlo method, sensitivity analysis, response surface projection) to demonstrate the variation in outputs resulting from altered inputs.

\section{Rabies-transmission models}

Numerous mammalian disease models have been published (e.g., Heesterbeek and Roberts, 1995; Barlow, 1996; Hudson et al., 2002). Over 60 models have been constructed dealing with rabies transmission in wildlife, with the majority involving transmission in red fox (Smith, 2001). Some of these models have simply demonstrated mathematical or modelling methods; few have rigorously examined multiple parameters of rabies transmission (e.g., Britton, 1991; Holmes, 1993; Johansen, 1994; Benyoussef et al., 1999; Ortega et al., 2000; Ortega et al., 2003).

Fig. 1 presents a compartmental schematic for rabies transmission in wildlife. Within any rabies-susceptible 


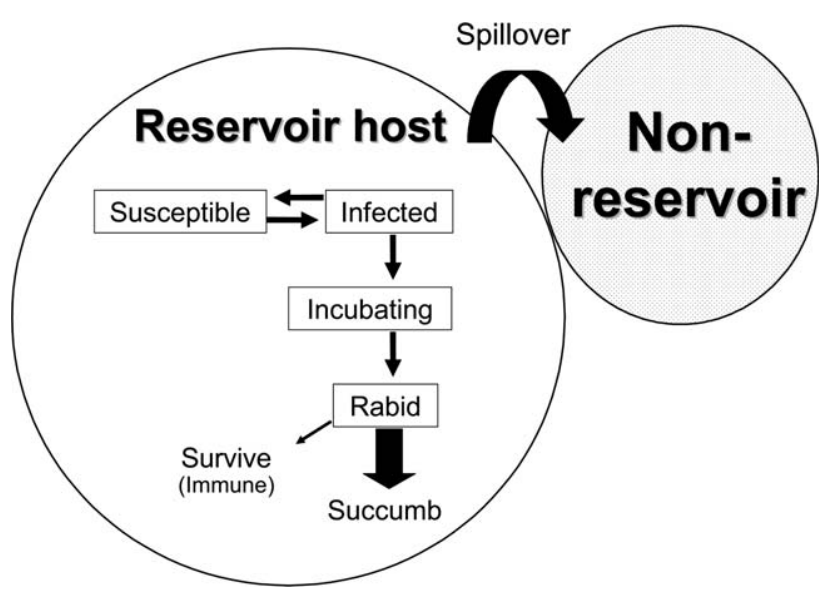

Fig. 1 - Schematic showing compartments in rabies transmission within and spillover between reservoir host and non-host populations. (Note. This diagram depicts spillover. In the case of certain bat species, the TM population is also the reservoir.)

species, host mammals above a specified density are viewed as a reservoir. Sequentially, a portion of the susceptible animals are infected, begin to incubate rabies, become rabid, and die or a few may survive and probably become immune. In many cases, TM will occur as relatively small, fragmented populations of susceptible animals - an estimated 600 Ethiopian wolves remain (Randall et al., 2006). These involve spillover infections from potential reservoir hosts in contiguous or overlapping habitats.

Bats present exposure risks to numerous TM because of their widespread distribution and flight (Johnston and Tinline, 2002). Bats are major hosts of rabies and many species of bats are classed as TM (see Smith, 2002b). These TM species of bats represent a conjunction of both reservoir host and TM.

\subsection{Parameterization of rabies transmission models}

Diverse demographic, disease transmission, disease control strategy, geo-spatial, and behavioural parameters influence rabies transmission in non-TM and TM (see Smith and Cheeseman, 2002). Representative parameters used in rabies transmission models include: mean per capita birth rate $(b)$, mean per capita death rate $(d)$, rabies transmission rate $(\beta)$, mean incubation period $(\sigma)$, and rabies-induced mortality rate $(\alpha)$.

Solving a set of differential equations with iterative changes in the variables that specify these equations characterize most modelling efforts. For example, a set of differential equations can specify the effects of culling upon rabies management (see Smith and Cheeseman, 2002). If rabies is assumed to have an incubation period during which infectious fox do not reproduce, the following equations could be written:

$\frac{d X}{d t}=b(X+Y)-d(N) X / N-\beta I X-p X$,

where the change in the number of healthy animals, $X$, is due to births, $b$, from both healthy and infected $(X+Y)$ animals, density-dependent death $(d(N) X / N)$, infection of healthy foxes $(\beta I X)$, and culling, $p X$; $\frac{d Y}{d t}=\beta I X-d(N) Y / N-\sigma Y-p Y$,

where the change in the number of infected or latent animals, $\mathrm{Y}$, is due to newly infected animals, $\beta I X$, density-dependent deaths $(d(N) Y / N)$, animals becoming infectious ( $1 / \sigma$ equals the incubation period), and culling, $p \mathrm{Y}$;

$\frac{d I}{d t}=\sigma Y-d(N) I / N-\alpha I-p I$,

where the change in the number of infected or infectious animals, $I$, is due to new infection, $\sigma \mathrm{Y}$, density-dependent deaths $(d(N) I / N)$, disease-induced mortality, $\alpha I$, and culling, pI. The per capita death rate, $d(N)$, was density-dependent and depended on the total population size, N. Thus, the densitydependent death rate of healthy animals is a fraction $\mathrm{X} / \mathrm{N}$ of the population rate $d / N$.

Similar equations could be written to describe populations in which no rabies incubation is assumed or fertility control and vaccination are used to model population effects (see Smith and Cheeseman, 2002).

\subsection{Early density-dependent transmission models}

One of the earliest modelling efforts of rabies in red fox was based on a simple mathematical understanding of disease in host populations (Anderson and May, 1979; Anderson et al., 1981). These models described $R 0$ - the number of new infections caused by one infected fox in a population of susceptible hosts. Foxes were assumed to have equal likelihood of contact with other foxes. If $R 0 \leqslant 1.0$, then, on average, each rabid fox would infect one or fewer foxes before it died. For an epizootic to occur, $R 0$ had to be $>1.0$. Based on scenarios representing rabies transmission in European red fox populations, average R0s of between 2.0 and 4.0 were estimated for these populations (Anderson et al., 1981). The value R0 depends on the host density per $\mathrm{km}^{2}$ (i.e., density-dependent). Greater densities of host animals lead to more infectious contacts under this assumed, non-territorial system of fox movement.

Many early disease models assumed that the disease transmission rate was linearly related to density, although empirical support was never presented. These models assume that lowered host densities will decrease rabies transmission proportionately. Linear density dependence predicts a threshold density $\left(K_{\mathrm{T}}\right)$ of susceptible foxes below which rabies will not become epizootic (i.e., die out). Thus, each infected fox will contact twice as many animals when the host density is doubled or half as many animals when the density is halved. A $K_{\mathrm{T}}$ value can be calculated from $R 0$ (i.e., if $R O$ is 4.0 and the host density is 2.0 then $K_{\mathrm{T}}$ is 2.0/ $4.0=0.5$ ). If empirical population sampling specifies a fox density, then these models can specify a culled number of foxes predicted to reduce fox densities and to "eradicate" the disease in a prescribed area (Anderson, 1982, 1991).

The limited field studies available have not confirmed a linear density-dependent relationship of disease transmission (Caley et al., 1998; Begon et al., 1999; Ramsey et al., 2002; Ji et al., 2005; Woodroffe et al., 2006). The assumption of linear density dependence affecting fox rabies transmission is questionable; threshold densities to decrease trans- 
mission almost certainly vary across ecosystems or red fox habitats (see MacInnes et al., 2001). The landscape ecology of rabies has been shown to differ greatly by locale, with no unique environmental or density factors identified for $\mathrm{R} 0$ (MacInnes et al., 2001). A universal $K_{\mathrm{T}}$ for rabies in foxes was thought to be about $1.0 \mathrm{fox} / \mathrm{km}^{2}$ (Anderson et al., 1981), but fox rabies survived in Canada, where fox densities were substantially < 1.0 (see Macdonald and Voigt, 1985; MacInnes et al., 2001). To quote Voight and Tinline (1982) as cited in MacInnes et al. (2001): "the fox density at which rabies is epizootic in Ontario is the density at which Europeans claim rabies will disappear (Bögel et al., 1974, 1976).”

\subsection{Early density-independent transmission models}

Density-independent (i.e., frequency-dependent) transmission assumes that each infectious animal contacts a fixed number of conspecifics, regardless of host density (McCallum et al., 2001; Begon et al., 2002). This concept invokes territoriality (i.e., behavioural spacing). It reduces the emphasis on host density (RO) and proportionality of threshold density $\left(K_{\mathrm{T}}\right)$. For territorial animals, each fox is assumed to contact its neighbours often, but to contact non-adjacent territorial animals less frequently, if ever. Numbers of animal contacts are therefore limited and dependent upon the structure of territories. It is not necessary for each animal to have an equal probability of contacting every other fox. While territory size may change with host density, family group size may remain constant (e.g., breeding pair plus offspring). Density-independent models suggest that an infectious animal contacts a fixed number of animals regardless of the density of hosts in an area (see Begon et al., 2002; McCallum et al., 2001). Because each host animal will likely encounter a limited num-

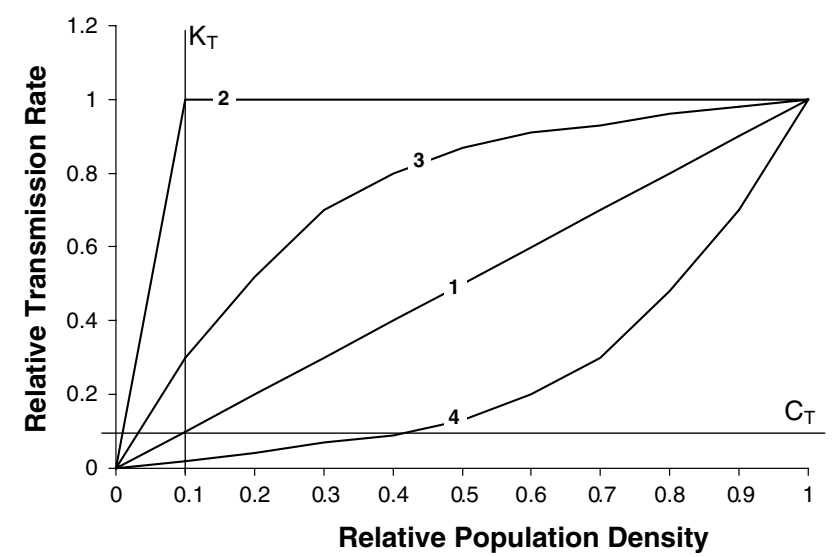

Fig. 2 - A representation of different relationships between disease transmission and population density. Line 1 is linear density dependent transmission, line 2 is density independent transmission, line 3 is convex up density dependent transmission, and line 4 is convex down density dependent transmission. The line drawn at the relative transmission rate of 0.1 represents $C_{T}$, the successful contact rate at which the disease will die out (i.e. $R 0<1$ ). From this it can be seen that $K_{T}$, the density of hosts below which the disease cannot sustain itself may be highly dependent on the transmission function. ber of other host animals, use of $K_{\mathrm{T}}$ does not apply - culling and contraception are deemed less important in preventing rabies transmission.

A rarely discussed aspect of density-independent models involves the question of altered territorial or contact behaviours due to infection. Rabies almost certainly alters typical behaviours of host animals (see Andral et al., 1982; Jackson, 2002). Pathology-caused behavioural effects would be expected to impact density-independent (assumed territorial shifts) models more than density-dependent (assumed homogeneous contacts) models due to the potential for more agonistic encounters at territorial boundaries. Non-territorial species would have a greater probability of avoiding agonistic encounters with rabid, aggressive animals.

\subsection{Recent stochastic, mixed transmission models}

Recent modelling efforts have incorporated novel parameters and mathematical computations into traditional densitydependent and density-independent expressions (Smith, 1995; Smith and Fooks, 2006). These models have been labelled "bottom-up" simulation models or stochastic, mixed models. These models include numerous demographic parameters that affect a rabies-host situation (including individual animal behaviours), then use novel matrices to compute the contact, infection, and spread outputs for rabies.

Foxes, like most territorial animals, mark their territories and contact their neighbours regularly (White and Harris, 1994; Goszczynski, 2002). Studies have shown that contacts among territorial neighbours increase for rabid foxes and that fox group size can increase with density (Andral et al., 1982; Harris and Smith, 1987; Macdonald et al., 1999; Marks and Bloomfield, 1999; Baker et al., 2000). This evidence suggests that a mix of both linear density-dependent and densityindependent transmission functions is needed to model rabies transmission in these situations. Transmission of rabies is assumed to vary with host density and is dependent upon the emergent features of how hosts aggregate-relationships between transmission rate and host density must be specified a priori. Although somewhat criticized in the past, these

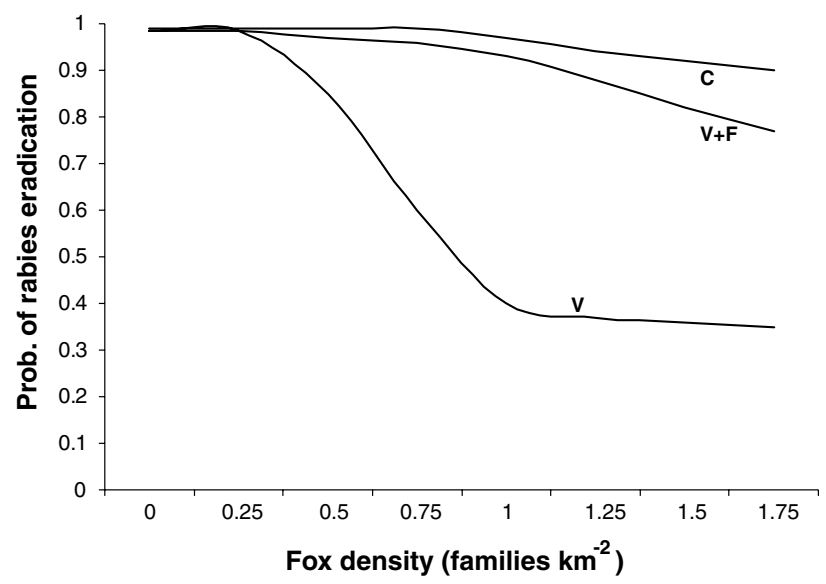

Fig. 3 - A simulated comparison of culling (C), vaccination (V), and vaccination plus fertility control $(V+F)$ for a single campaign that affects $80 \%$ of the host population. Redrawn from (Smith and Wilkinson, 2003). 
stochastic, individual-based models have simulated certain disease patterns well (Keeling and Grenfell, 2000; Kao, 2002; Smith, in press).

Fig. 2 presents four density-dependent and density-independent functions comparing relative rabies transmission based upon relative population density. Dual convex up or concave down functions are illustrated because all of these relationships have received some support (Smith, 2005). Note that there is a disparity between a projection for $K_{T}$ (i.e., transmission threshold) and for $C_{\mathrm{T}}$ (successful contact rate). Inspection reveals that $C_{\mathrm{T}}$ may occur at different densities, which could be due to different habitats or population control strategies (Fig. 2). A population at carrying capacity with a relative density of 0.5 may have a relative transmission rate of 0.5 (i.e., the population size is shown as Line 1). However, a population that has been reduced to a relative density of 0.5 by culling could be represented as Line 3 with a much higher relative transmission rate. A population that achieves a relative density of 0.5 while expanding into sub-optimal habitat could be represented by Line 4 with a much lower relative transmission rate. In short, density alone does not determine when $R 0 \leqslant 1.0$ (see MacInnes et al., 2001).

\subsection{Implications of transmission models to rabies management with non-TM}

A major difference in the implications of culling and fertility control upon host animals is evident in the models reviewed up to now (e.g., Anderson et al., 1981; Barlow, 1996; Smith and Cheeseman, 2002). In these models, culling the reservoir species has two advantages over vaccination. First, it removes infected animals, whereas vaccination does not; this makes it possible to extinguish an epizootic outbreak quickly. Second, although trite, culled animals do not reproduce; whereas, vaccinated animals produce rabies susceptible young.

Using the early density-dependent and density-independent rabies models, it has been shown that culling insufficient animals to "eradicate" the disease can extend the duration of an epizootic (Smith and Harris, 1989). That is, culling (and fertility control) might decrease the prevalence but increase the persistence of rabies (Aubert, 1994) - making the situation worse than without culling (and contraception). A similar non-intuitive result has been recorded when culling badgers to control endemic bovine tuberculosis (Donnelly et al., 2005).

Using a stochastic, spatial, individual-based model, Smith and Wilkinson (2003) showed that as host density increases, the probability that a single campaign of culling can eliminate the disease decreases only slightly, while the probability of vaccination eliminating the disease decreases more substantially. The growth and dispersion of the point-source infection of animals makes it harder to control the disease. If the vaccine contains a fertility control agent $(V+F)$ then an intermediate success is seen (Fig. 3). Fig. 3 shows that the effectiveness of vaccination declines as host density increases and that a relatively higher efficacy of vaccination is required. The difference between vaccination $(\mathrm{V})$ and $V+F$ is the reduction of new susceptible young animals with $\mathrm{V}+\mathrm{F}$. The difference between $\mathrm{V}+\mathrm{F}$ and culling $(C)$ is the removal of infected animals. Thus, both mathematical (Smith and Cheeseman, 2002) and individual-based models (Smith and Wilkinson, 2003) showed that the efficacy of vaccination can be increased by contraception, without killing diseased animals.

Additionally, a stochastic spatial model has application in formulating a reactive management response by the British government to the potential translocation and outbreak of red fox rabies (Smith, 1995; Smith and Fooks, 2006). Terrestrial rabies has not been endemic in Britain since its eradication in 1922 (Smith and Fooks, 2006). The Government's objective would probably be to maximize chances for the quick complete "re-eradication" of translocated rabies, while minimizing the effect of culling on the fox population. Prior description of the stochastic, mixed rabies model showed that ORV is able to control wildlife rabies in most scenarios and locations, but that ORV-plus-culling could be beneficial in localized, high-fox-density areas (Smith and Wilkinson, 2003).

\subsection{Implications of transmission models to rabies management with TM}

Although subject to negative public opinion, many rabiestransmission models predict that culling would be effective in eliminating disease (Anderson, 1982, 1991). Some recent models have also predicted that culling and fertility control would be more effective (or at least greatly increase effectiveness) than vaccination at suppressing rabies in situations involving a focal outbreak (Barlow, 1996; Smith and Cheeseman, 2002). Of course, the culling of TM is not proposed. Still, the potential for culling of other reservoir hosts to protect "enclaves" (i.e., fragmented, isolated, limited habitats) of TM from non-TM reservoirs due to encroachment and transmission of rabies must remain a consideration.

One of the most frequent mathematical approaches used in the conservation of TM is population viability analysis (PVA). These models focus upon demographic, natality, and mortality parameters that can impact the recruitment and long-term stability of wildlife populations. Models involving PVA are not generally used to investigate disease; rather these models treat epizootics as catastrophic events of given sizes (Ballou, 1993; Gerber et al., 2005). It is not surprising that a model of rabies in rare animals was one of the first analyses to incorporate disease dynamics within a PVA framework (Haydon et al., 2002). If disease is a major aspect of the conservation of a species then standard PVA models are not currently recommended (Gerber et al., 2005).

Disease impacts have also been discussed in the context of meta-population models, which link a number of sub-populations that differ in size, location, or density (Hess, 1996; Gog et al., 2002; Ostfeld et al., 2005). Again, rabies has served as the example disease, with impacts upon meta-populations of skunks, raccoons, and canids described for urban Canada and Southern Africa, respectively (Broadfoot et al., 2001; Bingham, 2005).

\section{Rabies management}

The goal of rabies transmission modelling for wildlife is to offer strategies of managing the disease. Ultimately, these strat- 
egies determine the effectiveness of protecting TM from contracting rabies. Selected strategies also determine the source and the time-horizon of potential costs and savings associated with eliminating or containing the spread of rabies - strategies constrain how costs and savings from rabies campaigns are quantified.

Terms to describe the goals of rabies management campaigns have evolved during the past 40 years. Rabies control or management implies that the disease will remain endemic to an area, but that the prevalence of cases and epizootics will be lessened. "Eradication" (i.e., the complete absence of a reservoir post-rabies management) is rarely used (see Aubert, 1994; Cliquet and Aubert, 2004; Smith and Fooks, 2006). It has been replaced by "elimination" or "essentially-rabiesfree" (see Fearneyhough et al., 1998; Tischendorf et al., 1998; MacInnes et al., 2001; Slate et al., 2002; Sterner et al., 2004; Sidwa et al., 2005; Slate et al., 2005). These terms reflect our lack of knowledge about rabies control. The virus may continue to circulate in as yet unknown rabies-host compartments or recur via translocation of infected animals many years after assumed control was attained (see Russell et al., 2005). Evaluation of essentially rabies free mammal populations implies extensive surveillance and contingency costs to identify and prevent any residual occurrence (outbreak) of the virus, respectively.

Fertility control (contraception) for the wide-area control of wildlife populations is a topic of active research and development, but remains experimental (see Miller et al., 1998; Fagerstone et al., 2002). We use fertility control in the current context of density reduction as a theoretical concept; if viable methods of wildlife contraception were available, density reduction of susceptible hosts via wide-area contraception would be predicted to impede disease transmission.

\subsection{A taxonomy of rabies management for wildlife}

For modelling purposes, we view rabies management in wildlife to involve a 2-tiered contingency - prophylactic or reactive approaches combined with density reduction or no-densityreduction activities (see Table 1 ). We recognize that this tax- onomy is simplified (i.e., a successful reactive approach can be prophylactic) and that some strategies may entail multiple activities - at least one mixed density reduction and no density reduction strategy has been reported (see Rosatte et al., 2001). Still, we contend that it has utility for modelling.

Prophylactic control refers to suppressing enzootic rabies in a host population or to preventing the spread of rabies to potential host populations in uninfected areas (e.g., Slate et al., 2005). Reactive management refers to the suppression of localized epizootics (e.g., Randall et al., 2004) or a residual focus of the disease (e.g., MacKenzie, 2005). Each of these approaches can involve density reduction and no-densityreduction methods. Density reduction can be effected by culling or contraception-techniques that lower the numbers of susceptible host animals. No density reduction can be effected by trap-vaccinate-release (TVR) and ORV-techniques that leave the number of host animals intact, but render them immune to the disease. Vaccination also avoids social disruption due to the "vacuum effect" (i.e., new animals moving into available territories) and may be useful if applied around rabies foci-ring vaccination (see Macdonald, 1980; Smith and Wilkinson, 2003). Modelling can examine the effectiveness of these approaches and methods (e.g., Smith and Cheeseman, 2002; Russell et al., 2005).

\subsection{Empirical examples of rabies management strategies in non-TM}

Numerous studies describing rabies management strategies and campaigns have been published (Aubert, 1994; Fearneyhough et al., 1998; MacInnes et al., 2001; Rosatte et al., 2001; Slate et al., 2002; Cliquet and Aubert, 2004; Sidwa et al., 2005; Slate et al., 2005). All of these entailed rabies control in non-TM situations. These publications offer examples of prophylactic and reactive approaches using density reduction and no-density-reduction activities (Table 2).

\subsubsection{Reactive approach with density reduction}

Wide-area culling of red foxes was conducted in several European countries during the 1980s (Aubert, 1994; Tischendorf

Table 1 - Taxonomy of model-based rabies management approaches and methods in wildlife ${ }^{a}$

\begin{tabular}{|c|c|c|}
\hline \multirow[t]{2}{*}{ Approach } & No density reduction & Density reduction \\
\hline & Vaccination & $\begin{array}{c}\text { Culling/reproductive } \\
\text { inhibition }\end{array}$ \\
\hline Prophylactic (enzootic rabies) & $\begin{array}{l}\text { Applied to reduce susceptible } \\
\text { hosts (more humane) and to } \\
\text { provide a barrier to spread or } \\
\text { point infection control }\end{array}$ & $\begin{array}{l}\text { Applied in non-TM reservoirs } \\
\text { or important 'link' populations } \\
\text { to reduce risk of spread }\end{array}$ \\
\hline Reactive (epizootic rabies) & $\begin{array}{l}\text { Applied to reduce susceptible } \\
\text { hosts and slow transmission; } \\
\text { avoids social perturbation or the } \\
\text { "vacuum effect" of density } \\
\text { reduction }\end{array}$ & $\begin{array}{l}\text { Eliminates incubating and } \\
\text { infected individuals (reduces } \\
\text { recruitment in the short term) }\end{array}$ \\
\hline
\end{tabular}

a This taxonomy is restricted to methods for management of rabies in wildlife species; confinement of pets, although effective in preventing the spread of rabies to wildlife species, is not considered. 
Table 2 - List of major wildlife rabies campaigns (1980-present) showing approaches, strategies, location, target species, duration, and representative citation

\begin{tabular}{|c|c|c|c|c|c|}
\hline Approach/activity & Strategy & Location & Target species & Duration & Representative citation \\
\hline Reactive-density reduction & Wide-area cull & Europe & Red Fox & $10-20$ years & Aubert, 1994 \\
\hline Prophylactic-no density reduction & Wide-area ORV & Europe & Red Fox & $>10$ years $^{\mathrm{a}}$ & Brochier et al. (2001) \\
\hline Reactive-no density reduction & $\begin{array}{l}\text { Wide-area ORV "wedge } \\
\text { elimination" }\end{array}$ & Canada & Red Fox & 7 years $^{\mathrm{a}}$ & MacInnes et al., 2001 \\
\hline Prophylactic-no density reduction & Wide-area ORV "barrier" & United States & Raccoon & $>8$ years $^{\mathrm{a}}$ & Slate et al. (2005) \\
\hline Reactive-density reduction & $\begin{array}{l}\text { Wide area ORV + cull } \\
\text { "purse string" }\end{array}$ & United States & Coyote & $>11$ years $^{a}$ & Sidwa et al. (2005) \\
\hline Reactive-no density reduction & $\begin{array}{l}\text { Wide area ORV "purse } \\
\text { string" }\end{array}$ & United States & Gray Fox & $>11$ years $^{\mathrm{a}}$ & Sidwa et al. (2005) \\
\hline $\begin{array}{l}\text { Reactive-combined density reduction } \\
\text { and no density reduction }\end{array}$ & $\begin{array}{l}\text { TVR, ORV, and ORV + cull } \\
\text { (skunks) "point- } \\
\text { infection-control" }\end{array}$ & Canada & Raccoon & $>8$ years $^{a}$ & Rosatte et al. (2001) \\
\hline
\end{tabular}

a Surveillance, TVR, culling, or wide-area ORV bait distribution continues at present.

et al., 1998; Cliquet and Aubert, 2004). The campaigns were based largely upon predictions that density reduction alone would "eradicate" rabies (Anderson et al., 1981; Anderson, 1982). Essentially, results of studies showed that culling of fox alone on a relatively wide scale did not control rabies (see Aubert, 1994).

\subsubsection{Prophylactic approach with no-density-reduction}

Regional ORV efforts for fox rabies were conducted in western Europe during the 1980s and 1990s, with fox populations termed "essentially free" of rabies (Cliquet and Aubert, 2004). The use of ORV baits was reported to afford $80 \%$ vaccination of the fox populations annually in these campaigns (Brochier et al., 1991, 1998; Nagy et al., 1995).

\subsubsection{Reactive approach with no-density-reduction}

A Canadian campaign using ORV was conducted between 1989 and 1995; it effectively "eliminated" rabies in red fox from southern and eastern Ontario Province, Canada (MacInnes et al., 2001). The campaign targeted red fox, which were vectors of an arctic fox variant of rabies virus. This entailed multi-year aerial baiting of over $30,000 \mathrm{~km}^{2}\left(\approx 20 \mathrm{baits} / \mathrm{km}^{2}\right)$. The goal was to prevent wide area epizootic impacts using vaccination. It entailed both experimental and applied work. The efforts yielded an estimated $97 \%$ reduction in red fox rabies cases, plus eliminated skunk- and livestock-related cases for a period of time (MacInnes et al., 2001; see Rosatte et al., 2001, regarding renewed skunk cases).

\subsubsection{Prophylactic approach with no-density-reduction}

In the US, an extensive multi-year ORV campaign ( $\approx 50$ 75 baits $/ \mathrm{km}^{2}$ ) to vaccinate wild raccoons along The Appalachian Ridge, St. Lawrence River, and northern Maine, as well as to isolate the Cape Cod (Massachusetts) peninsula and Long Island (New York) has been in progress since 1995 (United States Department of Agriculture, 2001; Foroutan et al., 2002; Slate et al., 2002; Slate et al., 2005). This campaign seeks to deter the westward, northward, and eastward (Cape Cod and Long Island) spread of this rabies variant (Slate et al., 2005). Attempts to create this "barrier" (i.e., use of natural terrain to enhance establishment of a high-density vaccinated zone of host animals) have dispensed $>12,000,000$ ORV baits over $\approx 200,000 \mathrm{~km}^{2}$ (Slate et al., 2002; Slate et al., 2005). Bait distributions have involved both air and ground baitings, with a target distribution of $\approx 75$ baits $/ \mathrm{km}^{2}$. The overall success of this campaign is yet to be determined.

\subsubsection{Reactive approach with density reduction}

In the US, ORV ( $\approx 19-27$ baits $/ \mathrm{km}^{2}$ ) was used to stop the spread of coyote-transmitted (Canis latrans) canine rabies (dog-coyote variant) in south Texas (Fearneyhough et al., 1998; Sidwa et al., 2005). Prior to 1988, rabies was reported sporadically in coyotes; however, a strain of domestic dog rabies caused over 100 cases in several counties between 1991 and 1993 (Clark et al., 1994). Baiting in January and February were conducted to enhance ORV dosing of coyotes in winter (i.e., greater foraging of baits). Air distribution of 830,000 ORV baits in 1995 over a $60-80 \mathrm{~km}$-wide band along the northern edge of detected rabies cases stopped the northward spread of the disease. This ORV effort was subsequently continued, with a gradual shrinking of the baited area towards the Mexico-US Border (see Sidwa et al., 2005). It was termed "purse string" strategy (i.e., encirclement with gradual shrinking via ORV distribution), a variation of "ring" vaccination as used by other researchers (see Smith and Fooks, 2006). Currently, a maintenance zone approximately $80 \mathrm{~km}$ wide is being baited to effectively contain this dog-coyote variant of rabies (see Sidwa et al., 2005; Krebs et al., 2005). Although this campaign involved extensive use of ORV, this reactive strategy is viewed to entail density reduction (i.e., coyotes are controlled in Texas for purposes of livestock protection; see United States Department of Agriculture, 1994).

\subsubsection{Reactive approach with no-(or minimal)-density- reduction}

Gray fox rabies in west central Texas (US) was contained using annual ORV distributions $\left(29-39\right.$ baits $/ \mathrm{km}^{2}$ ) in a $16-24-\mathrm{km}$ wide buffer zone along the northern and eastern edges of this outbreak (Sidwa et al., 2005). An $\approx 350,000 \mathrm{~km}^{2}$ band was baited annually. Data revealed that 39 (270:699) and 62 (433:699) per cent of sampled foxes had biomarker and serum indications of bait consumption. In describing the 1995 through 2003 campaign (i.e., still continuing), this was also termed "purse-string" strategy (Sidwa et al., 2005). Counter to the ear- 
lier coyote ORV campaign, no (or minimal) density reduction characterized this strategy because gray foxes are not targeted in livestock protection efforts (United States Department of Agriculture, 1994). Currently, the expansion and northward spread of gray fox rabies in this area has been stopped, but elimination of the disease within the encircled zone has not been accomplished - this depends upon future funding (Sidwa et al., 2005).

\subsubsection{Reactive approach with combined density reduction and no-density-reduction}

A study in Ontario Province, Canada, entailed "point infection control" (Rosatte et al., 2001). This involved (also continues at present) the intensive TVR of raccoons and the culling of infected raccoons and most skunks to contain localized breakthroughs or translocations of raccoon-variant animals across the St. Lawrence River from the US, as well as to decrease the likelihood for skunks to serve as a lingering reservoir for the arctic fox variant of rabies (Rosatte et al., 2001; Slate et al., 2005). Ring-baiting with ORV baits around detected rabies cases was (is) also pursued. It has proved successful at preventing the spread of raccoon-variant rabies from the US into Ontario.

\subsection{Implications of empirical rabies management campaigns with non-TM}

Together, these publications reveal much about rabies campaign strategies in non-TM (Aubert, 1994; Fearneyhough et al., 1998; MacInnes et al., 2001; Rosatte et al., 2001; Slate et al., 2002; Cliquet and Aubert, 2004; Sidwa et al., 2005; Slate et al., 2005). All of these reports show that rabies campaigns have proved to be lengthy (multi-year) efforts that require continued surveillance and contingency plans to deal with sporadic new cases (Table 2).

Specifically, the European studies suggest that efficient culling can probably only be sustained in relatively small, localized areas, with some studies suggesting that rabies can be eliminated locally when efficient culling is performed (Müller, 1966; Irsara et al., 1982; Westergaard, 1982). European efforts with ORV were probably much better organized between regions and countries than were the prior culling efforts (Smith and Fooks, 2006). The Ontario studies confirm that elimination of red fox rabies via ORV alone is feasible and that "enhanced" surveillance (i.e., active trapping, road kill samples, and standard public health samples) plus "point infection control" with possible density reduction (skunks) offers an effective method of preventing rabies spread into uninfected areas (MacInnes et al., 2001; Rosatte et al., 2001). The eastern US "barrier" for raccoon-variant rabies using ORV without density reduction reinforces many of the aforementioned points; however, with the campaign in its 11 th year, very dense raccoon populations (e.g., $>30 / \mathrm{km}^{2}$ in some areas), and extensive surveillance and future baiting distributions still needed to establish this "barrier"- uncertainty persists. The Texas studies convey that spread of dog-coyote and gray fox rabies can be stopped via ORV with or without density reduction (Sidwa et al., 2005); however, continued surveillance and extensive funding may be needed to maintain a sentinel zone to detect new cases and to prevent resumption of rabies spreading northward (Fearneyhough et al., 1998; Sidwa et al., 2005).

\section{Economics of rabies management and TM}

The economics of rabies has been viewed traditionally as a public health issue (Meltzer and Rupprecht, 1998a,b). Granted, costs associated with livestock, pets, and other impacts of rabies (i.e., especially in Europe, North America and Latin America) have been reported (Meltzer and Rupprecht, 1998b); however, to our knowledge, no modelling or accounting-type studies to estimate the benefits-costs of protecting a TM population from rabies, per se, are published.

\subsection{Factors in the economics of rabies}

Researchers have identified a number of potential costs/savings related to rabies management (Uhaa et al., 1992; Meltzer, 1996; Sterner et al., 2004; Sterner and Sun, 2004). The following equation describes our view of how these costs/savings relate to wildlife rabies:

$$
\begin{aligned}
C_{R}= & P V+L V+P R+L R+Q+P r e E P+P E P+A R \\
& +P H+A C+H D+T M
\end{aligned}
$$

$C_{R}$ is the additive cost (\$US) of a multi-year epizootic of some wildlife-variant of rabies. This cost is attributed to 12 main independent variables: PV - pet vaccinations $(n \cdot \$ \mathrm{US} /$ vaccination), LV - livestock vaccinations ( $n \cdot \$ U S /$ vaccination), PR - pet animal replacements (n-\$US/animal for rabies-caused deaths), LR - livestock replacements ( $n \cdot \$ \mathrm{US} /$ head by species), Q-quarantine of suspected rabid animals ( $n \cdot \$$ US/event), PreEP - human pre-exposure-prophylaxis ( $n \cdot \$ U S /$ vaccination), PEP - human post-exposure-prophylaxis $(n \cdot \$$ US/treatments), AR - adverse reaction to PEP charges ( $n \cdot$ \$US/event), PH - public health charges $(n \cdot \$$ US/event for case investigations and laboratory tests), AC - animal control costs ( $n \cdot \$$ US/event for capture, removal of suspected infected animal), HD - insured human death claims ( $n \cdot \$ \mathrm{US} /$ death), and TM - resource loss of rare and threatened mammals ( $n \cdot \$ U S /$ animal or species). The TM factor is an extremely difficult estimate to derive (see Section 4.3).

Costs that are prevented due to rabies management campaigns will convert to savings. Obviously, costs and savings of rabies epizootics and rabies management vary by stage of the epizootic, geographical region, effectiveness of control, and thoroughness of measurement (Meltzer, 1996; Sterner et al., 2004). Most of the aforementioned 12 cost factors relate to human health or veterinary treatment plus finite replacement, liability, and insurance monies (Sterner and Sun, 2004). It has been shown that increased PV and human PEP frequencies are two main cost factors that increase dramatically during wildlife rabies epizootics (Uhaa et al., 1992; Meltzer, 1996; Noah et al., 1996; Sterner and Sun, 2004).

\subsection{Benefit-cost analysis of rabies impacts}

Benefit-cost analysis involves computing all of the gains and losses associated with a wildlife-disease (rabies) management effort over time and in similar units (Zerbe and Dively, 1994; 
Meltzer, 1996). The term benefit-cost, rather than cost-benefit, is significant. Benefit-cost is used with those economic analyses, where benefits (savings) are imprecise or difficult to quantify, but the costs are accurately specified. Cost-benefit is often reserved for more-quantifiable engineering situations, where both the precise benefits and costs of projects are known (see Zerbe and Dively, 1994).

Six steps characterize most benefit-cost analyses: (1) analysis of the situation/environment (e.g., habitats, density, dispersion, rabies hosts, etc. in the area of conservation), (2) analysis design (e.g., scope of the analysis, cost factors involved, potential benefits/savings to be gleaned), (3) actual data collection (e.g., assembly of ex post records, acquisition of ex ante surveys), (4) econometric analysis (e.g., convert the factor values into monetary units -"monetizing" the variables, regress the comprehensive outlays and returns), (5) performance of any sensitivity analyses (or other uncertainty reduction techniques) to determine the effects of a change in one or more independent variables (quantified costs) upon the dependent variable (savings), and (6) results assessment (e.g., determine projected, multi-year savings in rabies-related costs associated with a "barrier" to protect TM from host animals) (see Zerbe and Dively, 1994).

\subsection{Monetizing TM}

The prospect of having a TM population become extinct is difficult to accept. Nevertheless, this would place extremely high valuation upon that population, as well as each individual animal in that population. To date, environmental economists have provided only "primitive" methods to "monetize" (i.e., assign $€$ or US\$ valuations to a TM or specific animal) the potential loss of rare animals/species (see Loomis and Gonzalez-Caban, 1998; Engeman et al., 2002; Engeman et al., 2003b; Adamowicz, 2004).

Regarding methodology to value TM, diverse techniques have been used to gain estimates of the monetary value people place on natural resources (i.e., contingent valuation, hedonic pricing, travel procedures, and benefit transfer) (see Adamowicz, 2004). These methods often use surveys, or extrapolate measured benefits-costs from other natural resource assessments (benefit transfer), to allegedly gain a monetary estimate of the value humans would be "willingto-pay" to preserve or view resources/wildlife. While publication rates of studies using these methods have soared since the 1990s, most econometricians remain sceptical of the validity inherent to these methods (Adamowicz, 2004). Sampled subjects often provide a "willingness-to-pay" value for retaining resources only to later contradict survey results with low monetary contributions or defeat of funds-assigning legislation (see Van der Straaten, 2002; Adamowicz, 2004). More recently, novel valuation procedures of rare wildlife have used statutory fines for the killing of endangered animals in attempts to value endangered sea turtles and the Puerto Rican Parrot - extremely conservative estimates of animal value (Engeman et al., 2002; Engeman et al., 2003b). Extensive research and development of new, improved methodology is needed before realistic costs/savings from rabies management efforts to conserve TM can be assigned.

\subsection{Empirical estimates of rabies costs}

The comprehensive costs of rabies impacts to regional or world economies are difficult to estimate. For the US, these have been grossly estimated at $\approx \$ 408$ million (2005 USD) annually (i.e., Slate et al., 2005 citing $\$ 300$ million annually by Krebs et al., 1995; but expanded at 3\% for annual inflation). Human PEP and PV expenses during epizootics have been reported as the two greatest costs associated with non-TM epizootics in the US (Meltzer, 1996), while a recent study has shown that $\mathrm{PH}$ (public health agency education/case monitoring) and HD (insurance claims) costs could be relatively significant expenses (Sterner and Sun, 2004).

A study in Ontario, Canada, showed little correlation between numbers of animal cases and PEPs, but that introduction of a new, safer vaccine for people yielded an upsurge in administrations of PEPs (Nunan et al., 2002).

Studies of the potential local and regional costs of rabiescaused expenses within the US have been published (i.e., Uhaa et al., 1992; Kriendel et al., 1998; Chang et al., 2002; Shwiff et al., submitted for publication). Most of these have focused on direct and indirect medical expenses. A New Jersey study involving raccoon-variant rabies compared 1988 pre-epizootic and 1990 epizootic costs reporting that $\approx 20,000$ PEPs were provided during this period - a 65 -fold increase during these years (Uhaa et al., 1992). A study in Massachusetts examined state-wide reports of PEP between 1991 (pre-epizootic) and 1995 (soon after start of the epizootic) and found a 26-fold increase (Kriendel et al., 1998) - a surge from approximately 1.7-45 PEPs per 100,000 residents. A New York study examined public health data associated with the 1990s raccoon-variant epizootic; 11,552 persons were administered PEP for suspected exposure to 8762 animals between 1993 and 1998 (Chang et al., 2002). More recently, a California study showed that mean direct and indirect costs (2005 USD) of PEP per suspected case totalled \$2,564 (range: \$303-\$6455) and $\$ 1124$ (range: \$418-\$2,742), respectively; whereas, total case costs equalled $\$ 3688$ (range: $\$ 721-\$ 9,197$ ) (Shwiff et al., submitted for publication). These estimates ultimately, must be used by modellers as inputs to estimate the "savings" of rabies control efforts, where non-TM issues are justifying campaigns.

Studies have shown that expenditures associated with ORV campaigns vary with stages of a rabies epizootic (i.e., pre-, during-, and post-epizootic; Uhaa et al., 1992; Meltzer, 1996). Many pet owners neglect maintaining rabies vaccinations for pets, then rush to safeguard pets as publicity of rabies epizootics increase. Prices for rabies vaccine and animal examination vary widely throughout the world; during epizootics, many municipalities underwrite some PV costs and hold vaccination clinics (Sterner and Sun, 2004). The recommended regimen for rabies PV in the US is annually or triennially based upon the vaccine selected, the prior immunization history, and local regulations (National Association of State Public Health Veterinarians Committee, 2004). As pet owners become focused on prevention of rabies, PVs increase. Evidence from the aforementioned New Jersey study involving raccoon-variant rabies suggested that a PV averaged \$24 (2005 USD\$ at 3\% inflation), with PVs increasing by $5 / \mathrm{km}^{2}$ during the epizootic relative to pre-epizootic (Uhaa et al., 
1992; Meltzer, 1996). Additionally, during the later stages of rabies elimination in France, after years of distributing vaccine baits, the prophylactic vaccination of domestic dogs accounted for $72 \%$ of the total costs, and the cost of vaccine baits and their distribution accounted for just 3.1\% of the total (Aubert, 1999).

\subsection{Potential costs and savings of rabies management involving ORV for non-TM}

Campaigns involving ORV are both lengthy and expensive (Table 2). It has not been uncommon for these campaigns to exceed a decade or more (Stöhr and Meslin, 1996; Wandeler, 2000; Zanoni et al., 2000; MacInnes et al., 2001; Foroutan et al., 2002; Sidwa et al., 2005; Slate et al., 2005).

For the wide-area, multi-year, reactive control with ORV to control red fox rabies in Europe and Canada (Ontario Province), a number of ex post, accounting-type reports have been published (see Meltzer and Rupprecht, 1998b). Use of ORV in Switzerland during 1984-1985 was cited to have involved bait densities of $2.5-10 / \mathrm{km}^{2}$ with a total average direct and indirect cost of US\$3.95 per bait (range \$US1.54-\$US4.16) (Meltzer and Rupprecht, 1998b). For Belgium, cited costs of about $\$ \mathrm{US64} / \mathrm{km}^{2}$ for helicopter distribution of baits were reported (Meltzer and Rupprecht, 1998b). The 1978-1996 European costs for ORV with red fox rabies was placed at over US $\$ 80$ million for baits alone (Stöhr and Meslin, 1996). Canadian ORV efforts for red fox rabies involved bait prices of US\$0.71, with fixed-winged aircraft distribution set at \$US15-\$US20/ $\mathrm{km}^{2}$ for a mean distribution of 20 baits $/ \mathrm{km}^{2}$ (Campbell, 1994). Although "eradication" of the disease was sought, recent evidence documenting a few lingering rabid fox cases in certain European countries and Ontario indicate "essentially-rabies-free" may be a more attainable goal (Meltzer and Rupprecht, 1998b).

For the raccoon, coyote and gray fox wide-area ORV efforts in the US, baits and bait distributions have proved to be relatively expensive. Individual baits (Raboral V-RG7 baits, Merial Limited, Athens, Georgia, USA) are currently produced at a cost of about \$1.00-\$1.27 (2005 US\$, depending on bait type) for federal use and dispensed at $\approx 75$ baits $/ \mathrm{km}^{2}$ for raccoons (Slate et al., 2005). Bait distribution costs are roughly $\$ 9.40 / \mathrm{km}^{2}, \$ 17.25 / \mathrm{km}^{2}$, and $\$ 36.35 / \mathrm{km}^{2}$ for fixed-winged aircraft, ground, and rotary-winged aircraft applications, respectively (2005 US\$ at 3\% inflation; see Sterner et al., 2004). In one study of actual bait application costs, eight separate applications of a total of 385,160 ORV baits averaged $\$ 171.99 / \mathrm{km}^{2}$ (US\$ 2005), with ground distribution and helicopter baiting costing $\$ 21.60 / \mathrm{km}^{2}$ and $\$ 26.24 / \mathrm{km}^{2}$ (US\$2005), respectively (Foroutan et al., 2002). The 2003 ORV campaign costs for baits, flight time and aircraft fuel alone to deter raccoon-variant rabies from spreading westward along the Appalachian Ridge totalled \$1.3 million, with personnel/travel costs unreported (Slate et al., 2005).

Interestingly, as part of efforts to suppress the raccoonvariant rabies in New Jersey, selected cost/savings data for a two county area (i.e., Hunterdon and Warren Counties) during the 1989-90 epizootic were reported (Uhaa et al., 1992). Preepizootic (1998) cost data were compared to epizootic (1990) costs and ORV was used to help suppress this epizootic. Di- verse cost estimates in the two-county area (i.e., pre-exposure prophylaxis (PEP), pet vaccination, animal bite investigation, domestic animal confinement, laboratory diagnosis, and miscellaneous rabies control activities) were derived. Results showed that these dual county costs increased between two and threefold during the epizootic. The authors estimated ORV efforts at US $\$ 141 / \mathrm{km}^{2}$ (2005 USD\$ expanded at 3\%), and concluded that benefit-cost ratios $>2.2$ were likely for diverse scenarios in which ORV would have been used to prevent the epizootic (Uhaa et al., 1992).

\subsection{Benefit-cost modelling of ORV campaigns for non-TM}

As stated, the benefits of rabies management are simply the savings (future non-incurred costs) associated with potential human health, agriculture, veterinary, legal, and TM losses (costs or values). Thus, economic models of rabies management scenarios for the conservation of TM must specify likely potential rabies impacts (i.e., savings to include the valuation of the rare or endangered population) in the absence of control efforts, and then subtract the projected rabies-control costs (i.e., ORV or ORV-plus-culling or ORV-plus-fertility control activities). This also entails prorating these savings over prescribed future years - cost-recovery "time horizon" (see Meltzer, 1996; Kemere et al., 2002).

Actual benefit-cost modelling studies of ORV for rabies management have been limited to scenarios involving raccoon-variant rabies in the US (Meltzer, 1996; Kemere et al., 2002). For ease of modelling, rabies-control costs are usually computed as cost per unit area (e.g., $€ / \mathrm{km}^{2}, \mathrm{US} \$ / \mathrm{mi}^{2}$ ) (Meltzer, 1996; Foroutan et al., 2002; Sterner et al., 2004).

One model can be likened to reactive - no-density-reduction management, with benefits accrued over 30 years for areas outside an expanding zone of the disease (Meltzer, 1996). Thirty years of expenditures and savings attributed to ORV varied with stages of the rabies epizootic - pre-, during-, and post-epizootic. Pet vaccination and post-exposure prophylaxis (PEP) treatment were the two main factors gleaned from sensitivity analyses that justified ORV (Meltzer, 1996). It was argued that as people become focused on prevention of rabies during epizootics, pet vaccinations and PEPs increase - individuals are motivated to have their pets protected by vaccination and to seek liberal medical treatments after practically any suspicious wild animal contact.

More recently, a detailed benefit-cost model was used to assess the use of ORV in preventing the westward spread of raccoon-variant rabies along the Appalachian Ridge (Kemere et al., 2002). This fits a wide-area prophylactic strategy, with benefits recouped by savings from unaffected areas over a 20-year period. Key input variables were: area baited of $102,650 \mathrm{~km}^{2}$, bait density of $75 / \mathrm{km}^{2}$, bait price US $\$ 1.30$, aerial distribution US $\$ 8.62 / \mathrm{km}^{2}$, and ORV evaluation US $\$ 15.00 \mathrm{~km}^{2}$. Eight scenarios were used; these involved assumed annual rates of spread (i.e., 42 vs. $125 \mathrm{~km} /$ year), increased or no increased numbers of pet vaccinations for the area of annual spread and reductions in baiting costs after five years were the "barrier" to hold. Savings data were computed based upon avoided medical and non-medical costs reported by Uhaa et al. (1992) - it was assumed that the western states would 
experience costs similar to New Jersey (see Uhaa et al., 1992). Results showed that for all but one scenario (i.e., $42 \mathrm{~km} / \mathrm{year}$ spread, excluding $20 \%$ increased PV costs during epizootic, ORV applied at 75 baits $/ \mathrm{km}^{2}$ for 20-year "time horizon"), the benefit-cost ratios exceeded 1.1, and slower westward movement of rabies was associated with greater savings (ratios).

\section{Implications and recommendations}

\subsection{General implications to rabies management for TM}

No modelling efforts have examined either the benefits-costs of rabies management strategies to conserve TM or the use of ORV, per se, to conserve TM. We view this omission due in part to the lack of methodologies for properly valuing TM (potential savings) and to the expense or lower priority of using ORV for TM protection.

The need for improved, valid "monetizing" methodology for rare and endangered animals is real; currently, the lack of this methodology precludes the development of pragmatic benefit-cost models for rabies management scenarios with TM. It will not suffice to argue that all forms of endangered flora and fauna warrant protection at all costs. Governments and conservation societies function on limited funds. Detailed benefit-cost models are needed to better quantify aspects of TM conservation.

The benefits and costs of localized culling in combination with ORV to prevent establishment of rabies in non-endemic areas (e.g., United Kingdom) have not been studied. It seems reasonable that this reactive control scenario involving limited land areas, with relatively short durations for culling and baiting, might yield substantial gains for ORV-plus-culling relative to ORV alone (Smith and Cheeseman, 2002). Likewise, culling of non-TM hosts in "buffer" and fragmented enclaves of rare canid populations could reduce risks of infections (Smith, 1995). This has particular relevance to the potential translocation of rabies-infected animals into currently rabies-free areas. In fact, the issue of uncontrolled animal translocations warrants examination by society - this looms large in the control of animal diseases worldwide.

Conservation risks for many TM occur mainly from mutations of the rabies virus and from "spillover" events (see Engeman et al., 2003a; Slate et al., 2005). The lack of immunization afforded to dog-wolf hybrids in California by traditional canine rabies vaccine (Jay et al., 1994), the occurrence of a dog-coyote variant of rabies in Texas (Fearneyhough et al., 1998), and the transfer of a bat-variant rabies to striped skunks in Arizona (see Engeman et al., 2003a; Slate et al., 2005) have shown that unique variants of RABV will probably continue to occur (see; Smith, 2002b; Badrane and Tordo, 2001). Were potential new variants or "spillover" infections to occur in rare canids (e.g., Blanford's fox, Ethiopian wolf, and African wild dog), rabies impacts would become more devastating to these populations (see Macdonald, 1993; Randall et al., 2004; Randall et al., 2006). Similarly, with 27 of 30 documented species of European bats listed as TM, the potential exposure of these bats to RABV, EBLV-1 and EBLV-2 makes long-term survival questionable (see Smith, 2002b).
Rabies vaccination of TM or of reservoir hosts in the surrounding habitat and within core areas poses many challenges (see Johnston and Tinline, 2002). Parenteral vaccination $(>70 \%)$ of domestic and feral dog populations, plus certain TM (i.e., Ethiopian wolf), has been proposed to lower extinction risks; such programs would offer a major step forward in protecting certain canid species of TM in Africa and Asia (see Randall et al., 2006). The use of ORV is rabies-variant, and thus target-species, specific. The simultaneous occurrence of several variants of the rabies virus in multiple reservoir species (e.g., red fox, raccoon, skunk and bats) in an area complicates economic projections of savings from ORV or culling-plus-ORV or contraception-plus-ORV. Elimination of rabies epizootics in given terrestrial hosts will not avoid future impacts or costs from "spillover" cases and new variants of the disease, especially those posed by bats (see Johnston and Tinline, 2002). Likewise, this will not preclude the reintroduction of future cases of the disease from outside the area. Still, the use of vaccination for other rabies hosts in the vicinity of TM to prevent a "populationthreatening" epizootic or "spillover" infections must remain a consideration (see Haydon et al., 2002; Randall et al., 2006).

Certainly, culling of TM would probably never be recommended to enhance rabies management, but the culling of reservoir hosts that share or link with habitats of TM may afford greater effectiveness and the timely establishment of non-infectious animals near TM (Eisinger et al., 2005). Recent rabies-transmission models and empirical data indicate that some culling or contraception of reservoir host animals should be considered in management strategies to enhance the effectiveness of ORV or contraception methods, and possibly to protect "enclaves" of TM from the virus carried by non-TM (Rosatte et al., 2001; Smith and Cheeseman, 2002). Culling of non-TM in this scenario seems to show advantages if the host population is somewhat isolated from other reservoirs. Widespread population reduction of foxes in Europe has not proved effective at rabies "eradication", probably due to lack of central organization and low efficiency (see Debbie, 1991; WHO, 1992).

Let us hope that the moral dilemma, which would result from overlapping habitats of "charismatic" (e.g., Blanford's fox, Ethiopian wolf, and African wild dogs) and less "charismatic" TM populations (i.e., possibly a non-host reservoir and a host reservoir) contiguously in space and time, is never encountered - require consideration of management choices and tradeoffs to protect one population at the expense of another. Or does this exist for specific "less-charismatic" bat TM and "charismatic" canid TM populations already?

\subsection{Some recommendations for modellers}

Modelling of wildlife rabies (diseases in general), economics, and TM conservation offers many advantages (e.g., useful conceptualizations/predictions/inferences, inexpensive/iterative production of transmission, spread, and control scenarios, a priori projections of returns on investments, feasibility of protecting a rare population from rabies), but limitations also need to be recognized. In considering how modelling efforts for rabies (disease) transmission, benefit-cost analysis, 
and conservation of TM can be improved, we identify five steps:

(1) Models, particularly simple mathematical models, should be constructed early in the assessment of disease control. In the interest of controlling a wildlife disease, we contend that some modelling is better than no modelling. Models may be constructed even when there are relatively few data available. These can then be used to determine the relative importance of selected parameters (i.e., sensitivity analysis) and to compare the outcomes of models with different structures (i.e., model uncertainty analysis). This step is analogous to statistical sampling and power analysis before collecting data in experiments.

(2) Results from early model building should then be used to direct the collection, or collation, of the relatively more important parameters and data. Granted, this involves scientific judgment, but early outputs provide evidence of model function and parameter salience. If data are not immediately available, then it may be possible to use techniques of expert elicitation (see Hughes and Madden, 2002; Normand et al., 1998).

(3) Subsequent, new data should be used to update the initial model(s), to validate the inclusion of parameters and to construct altered/more detailed models, if required. These models can then be subjected to detailed uncertainty reduction methods and plans made for further data collections derived. Given the complexity of the disease transmission, disease management, economic, and conservation systems under study, multiple candidate models are recommended for all large projects of national or international scope. Appropriate model structure can then be determined using an information-theoretic approach (Burnham and Anderson, 2002; White and Lubow, 2002) or multiple model predictions can be obtained to examine robustness. "Cycling" of models, hypotheses, parameters, and data to examine new outputs is critical to sound model building (Burnham and Anderson, 2002).

(4) The final model(s) should then be used to make "bounded" (i.e., set limits) projections for different situations, as long as this is within the confines of the original model's purpose.

(5) Finally, model outputs should be combined with the costs and benefits of different disease management options and an economic evaluation performed. If even conservative valuation of a rare wildlife species is not possible, then the models should be evaluated using cost-effectiveness (rather than benefit-cost) scenarios. We contend that some economic projection of modelled predictions is essential. These projections should be comprehensive and include diverse, multi-year disease-factor costs (e.g., PV, PEP, PH, PR, LV, LR) plus disease-control costs (e.g., bait density (baits $\left./ \mathrm{km}^{2}\right)$, baited area $\left(\mathrm{km}^{2}\right)$, bait-application frequency (number/campaign), bait price (cost/bait), mode of bait application (fixed-winged aircraft, rotarywinged aircraft, ground vehicle), culling effectiveness (\% density reduction of target animals $/ \mathrm{km}^{2}$ ); see Foroutan et al., 2002; Meltzer, 1996; Sterner et al., 2004). Potential savings should be pro-rated over realistic time frames (i.e., dependent upon campaign goals), expand costs/savings at average annual inflation rates and include possible contingency costs (i.e., scenarios for potential/sporadic failures of the campaign due to translocation of rabid hosts beyond barrier, a localized epizootic in previously controlled area, etc.).

\section{Acknowledgements}

The authors thank Dan Haydon, Kathleen Fagerstone, Greg Phillips, Troy Phillips, Phil Riordan and two anonymous referees for many useful comments on an earlier draft. A special note of thanks goes to David Macdonald for editorial advice. We acknowledge Defra for funding.

\section{R E F E R E N C E S}

Adamowicz, W.L., 2004. What's it worth? An examination of historical trends and future directions in environmental valuation. The Australian Journal of Agricultural and Resource Economics 48, 419-443.

Anderson, R.M., 1982. Fox rabies. In: Anderson, R.M. (Ed.), Population Dynamics of Infectious Diseases. Chapman and Hall, London, pp. 242-261.

Anderson, R.M., 1991. Rabies - immunization in the field. Nature 354, 502-503.

Anderson, R.M., May, R.M., 1979. Population biology of infectious diseases: Part 1. Nature 280, 361-367.

Anderson, R.M., Jackson, H.C., May, R.M., Smith, A.D.M., 1981. Population dynamics of fox rabies in Europe. Nature 289, 765-771.

Andral, L., Artois, M., Aubert, M.F.A., Blancou, J., 1982. Radio-pistage de renard enrages. Comparative Immunology, Microbiology and Infectious Diseases 5, 285-291.

Aubert, M., 1994. Control of rabies in foxes: what are the appropriate measures? Veterinary Record 134, 55-59.

Aubert, M.F.A., 1999. Costs and benefits of rabies control in wildlife in France. Revue Scientifique et Technique de l'Office International des Epizooties 18, 533-543.

Aubert, M.F.A., Blancou, J., Barrat, J., Artois, M., Barrat, M.J., 1991. Transmission et pathogénie chez le renard roux de deux isolats à dix ans d'inervalle du virus de la rage vulpine. Annales Recherches Veterinaires 22, 77-93.

Badrane, H., Tordo, N., 2001. Host switching in Lyssarvirus history from the Chiroptera to the Carnivora orders. Journal of Virology 75, 487-490.

Baker, P.J., Funk, S.M., Harris, S., White, P.C.L., 2000. Flexible spatial organisation of urban foxes (Vulpes vulpes) before and during an outbreak of sarcoptic mange. Animal Behaviour 59, 127-146.

Ballou, J.D., 1993. Assessing the risks of infectious diseases in captive breeding and reintroduction programs. Journal of Zoo and Wildlife Medicine 24, 327-335.

Barlow, N.D., 1996. The ecology of wildlife disease control: simple models revisited. Journal of Applied Ecology 33, 303314.

Begon, M., Hazel, S.M., Baxby, D., Bown, K., Cavanagh, R., Chantrey, J., Jones, T., Bennett, M., 1999. Transmission dynamics of a zoonotic pathogen within and between wildlife host species. Proceedings of the Royal Society of London B 266, 1939-1945.

Begon, M., Bennett, M., Bowers, R.G., French, N.P., Hazel, S.M., Turner, J., 2002. A clarification of transmission terms in 
host-microparasite models: numbers, densities and areas. Epidemiology and Infection 129, 147-153.

Benyoussef, A., Boccara, N., Chakib, H., EzZahraouy, H., 1999. Lattice three-species models of the spatial spread of rabies among foxes. International Journal of Modern Physics C 10, 1025-1038.

Bingham, J. 2005. Canine rabies ecology in Southern Africa. Emerging Infectious Diseases 11 [available online http:// www.cdc.gov/ncidod/eid/vol11no09/05-0172.htm].

Britton, N.F., 1991. An integral for a reaction-diffusion system. Applied Mathematics Letters 4, 43-47.

Bögel, K., Arata, A.A., Moegle, H., Knorpp, F., 1974. Recovery of reduced fox populations in rabies control. Zentralblatt für Veterinärmedizin (B) 21, 401-412.

Bögel, K., Moegle, H., Knorpp, F., Arata, A.A., Dietz, K., Diethelm, P., 1976. Characteristics of the spread of a wildlife rabies epidemic in Europe. Bulletin of the World Health Organization 59, 269-279.

Broadfoot, J.D., Rosatte, R.C., O'Leary, D.T., 2001. Raccoon and skunk population models for urban disease control planning in Ontario, Canada. Ecological Applications 11, 295-303.

Brochier, B., Kieny, M.P., Costy, F., Coppens, P., Bauduin, B., Lecocq, J.P., Languet, B., Chappuis, G., Desmettre, P., Afiademanyo, K., Libois, R., Pastoret, P.P., 1991. Large scale eradication of rabies using recombinant vaccinia-rabies vaccine. Nature 354 , 520-522.

Brochier, B., Dechamps, P., Costy, F., Chalon, P., Hallet, L., Peharpre, D., Mosselmans, F., Beier, R., Lecomte, L., Mullier, P., Roland, H., Bauduin, B., Renders, C., Pastoret, P.P., 1998. Epidemiosurveillance of rabies in Belgium: 1997 assessment. Annales de Médecine Vétérinaire 142, 261. 8 pages.

Brookes, S.M., McElhinney, L.M., Johnson, N., Badrane, H., Tordo, N., Fooks, A.R., 2004. Rabies virus variants and molecular epidemiology in Europe. In: King, A.A., Fooks, A.R., Aubert, M., Wandeler, A.I. (Eds.), Historical Perspectives of Rabies in Europe and the Mediterranean Basin. OIE, Paris, pp. 243-258.

Burnham, K.P., Anderson, D.R., 2002. Model Selection and Multi-model Inference: A Practical Information-theoretic Approach. Springer-Verlag, New York.

Caley, P., Spencer, N.J., Cole, R.A., Efford, M.G., 1998. The effect of manipulating population density on the probability of den-sharing among common brushtail possums, and the implications for transmission of bovine tuberculosis. Wildlife Research 25, 383-392.

Campbell, J.B., 1994. Oral rabies immunization of wildlife and dogs: challenges to the Americas. In: Rupprecht, C.E., Dietzschold, B., Koprowski, H. (Eds.), Lyssaviruses. Springer-Verlag, Berlin, pp. 247-266.

Chang, H., Eidson, M., Noonan-Toly, C., Trimarchi, C.V., Rudd, R., Wallace, B.J., Smith, P.F., Morse, D.L., 2002. Public health impact of re-emergence of rabies, New York. Emerging Infectious Diseases 8 (9), 909-913.

Charlton, K.M., Casey, G.A., 1979. Experimental rabies in skunks: oral, nasal, tracheal and intestinal exposure. Canadian Journal of Comparative Medicine (and Veterinary Science) 43, 168172.

Clark, K.A., Neill, S.U., Smith, J.S., Wilson, P.J., Whadford, V.W., McKrahan, G.W., 1994. Epizootic canine rabies transmitted by coyotes in south Texas. Journal of the American Veterinary Medical Association 204, 536-540.

Cliquet, F., Aubert, M., 2004. Elimination of terrestrial rabies in Western European countries. Developments in Biologicals 119, 185-204.

Cliquet, F., Picard-Meyer, E., 2004. Rabies and rabies-related viruses: a modern perspective on an ancient disease. Revue Scientifique et Technique 23, 625-642.
Cochran, W.C., Cox, G.M., 1957. Experimental Designs, second ed. John Wiley and Sons Inc., New York. pp. 5, 50.

Debbie, J.G., 1991. Rabies control of terrestrial wildlife by population reduction. In: Baer, G.M. (Ed.), The Natural History of Rabies. CRC Press, Boston, pp. 477-484.

Donnelly, C.A., Woodroffe, R., Cox, D.R., Bourne, F.J., Cheeseman, C.L., Clifton-Hadley, R.S., Wei, G., Gettinby, G., Gilks, P., Jenkins, H., Johnston, W.T., Le Fevre, A.M., McInerney, J.P., Morrison, W.I., 2005. Positive and negative effects of widespread badger culling on tuberculosis in cattle. Nature. doi:10.1038/nature 04454.

Eisinger, D., Thulke, H.H., Müller, T., Selhorst, T., 2005. Emergency vaccination of rabies under limited resources - combating or containing? BMC Infectious Diseases 5, art no. 10.

Engeman, R.M., Shwiff, S.A., Smith, H.T., Constantin, D.B., 2002. Monetary valuation methods for economic analysis of the benefit-costs of protecting rare wildlife species from predators. Integrated Pest Management Reviews 7, 139-144.

Engeman, R.M., Christensen, K.L., Pipas, M.J., Bergman, D.L., 2003a. Population monitoring in support of a rabies vaccination program for skunks in Arizona. Journal of Wildlife Diseases 39, 746-750.

Engeman, R.M., Shwiff, S.A., Cano, F., Constantin, D.B., 2003b. An economic assessment of the potential for predator management to benefit Puerto Rican parrots. Ecological Economics 46, 283-292.

Fagerstone, K.A., Coffey, M.A., Curtis, P.D., Dolbeer, R.A., Killian, G.J., Miller, L.A., Wilmot, L.M., 2002. Wildlife Fertility Control. Wildlife Society Technical Review 02-2, The Wildlife Society, Bethesda, MD, USA, 29 pp.

Fearneyhough, M.G., Wilson, P.J., Clark, K.A., Smith, D.R., Johnston, D.H., Hicks, B.N., Nettles, V.F., 1998. Results of an oral rabies vaccination program for coyotes. Journal of the American Veterinary Medical Association 212, 498-502.

Foroutan, P., Meltzer, M.I., Smith, K.A., 2002. Cost of distributing oral raccoon-variant rabies vaccine in Ohio: 1997-2000. Journal of the American Veterinary Medical Association 220, 27-32.

Gerber, L.R., McCallum, H., Lafferty, K.D., Sabo, J.L., Dobson, A., 2005. Exposing extinction risk analysis to pathogens: is disease just another form of density dependence? Ecological Applications 15, 1402-1414.

Gog, J., Woodroffe, R., Swinton, J., 2002. Disease in endangered metapopulations: the importance of alternative hosts. Proceedings of the Royal Society of London B 269, 671-676.

Goszczynski, J., 2002. Home ranges in red fox: territoriality diminishes with increasing area. Acta Theriologica 47, 103-114.

Harris, S., Smith, G.C., 1987. Demography of two urban fox (Vulpes vulpes) populations. Journal of Applied Ecology 24, 7586.

Haydon, D.T., Laurenson, M.K., Sillero-Zubiri, C., 2002. Integrating epidemiology into population viability analysis: managing the risk posed by rabies and canine distemper to the Ethiopian wolf. Conservation Biology 16, 1372-1385.

Heesterbeek, J.A.P., Roberts, M.G., 1995. Mathematical models for microparasites of wildlife. In: Grenfell, B.T., Dobson, A.P. (Eds.), Ecology of Infectious Diseases in Natural Populations. Cambridge University Press, Cambridge, pp. 91-122.

Hess, G., 1996. Disease in metapopulation models: implications for conservation. Ecology 77, 1617-1632.

Holmes, E.E., 1993. Are diffusion-models too simple - a comparison with telegraph models of invasion. American Naturalist 5, 12-15.

Hudson, P.J., Rizzoli, A., Grenfell, B.T., Heesterbeek, H., Dobson, A.P., 2002. The Ecology of Wildlife Disease. Oxford University Press, Oxford.

Hughes, G., Madden, L.V., 2002. Some methods for eliciting expert knowledge of plant disease epidemics and their application in 
cluster sampling for disease incidence. Crop Protection 21, 203-215.

International Union for Conservation of Nature and Natural Resources. Web site. The IUCN Red List of Threatened Species $^{\mathrm{TM}}$ Summary Statistics. Available at: http:// www.redlist.org/info/tables/table5 (accessed January 31, 2006).

Irsara, A., Ruatti, A., Gagliardi, G., Orfei, Z., Bellani, L., Mantouani, A., 1982. Control of wildlife rabies in north-eastern Italy. Comparative Immunology, Microbiology and Infectious Diseases 5, 327-335.

Jackson, A.C., 2002. Future developments and challenges. In: Jackson, A.C., Wunner, W.H. (Eds.), Rabies. Academic Press, Boston, pp. 473-479.

Jay, M.T., Reilly, K.E., Debess, E.E., Haynes, E.H., Bader, D.R., Barrett, L.R., 1994. Rabies in a vaccinated wolf-dog hybrid. Journal of the American Veterinary Medical Association 205, 1729-1732.

Ji, W., White, P.C.L., Clout, M.N., 2005. Contact rates between possums revealed by proximity data loggers. Journal of Applied Ecology 42, 595-604.

Johansen, A., 1994. Spatiotemporal self-organisation in a model of disease spreading. Physica D 78, 186-193.

Johnston, D.H., Tinline, R.R., 2002. Rabies control in wildlife. In: Jackson, A.C., Wunner, W.H. (Eds.), Rabies. Academic Press, Boston, pp. 446-471.

Kao, R.R., 2002. The role of mathematical modelling in the control of the 2001 FMD epidemic in the UK. Trends in Microbiology 10, 279-286.

Keeling, M.J., Grenfell, B., 2000. Individual-based perspectives on R0. Journal of Theoretical Biology 203, 51-61.

Kemere, P., Liddel, M.K., Evangelou, P., Slate, D., Osmek, S., 2002. Economic analysis of a large scale oral vaccination program to control raccoon rabies. In: Clark, L., Hone, J., Shivik, J.A., Watkins, R.A., Vercauteren, K.C., Yoder, J.K. (Eds.), Human Conflicts with Wildlife: Economic Considerations. US Department of Agriculture, Animal and Plant Health Inspection Service, National Wildlife Research Center, Fort Collins, CO, pp. 109-115.

Krebs, J.W., Strine, T.W., Smith, J.S., Rupprecht, C.E., Childs, J.E., 1995. Rabies surveillance in the United States during 1994. Journal of the American Veterinary Medical Association 207, 1562-1575.

Krebs, J.W., Wheeling, J.T., Childs, J.E., 2003. Public veterinary medicine: public health - rabies surveillance in the United States during 2002. Journal of the American Veterinary Medical Association 223, 1736-1748.

Krebs, J.W., Mandel, E.J., Swerdlow, D.L., Rupprecht, C.E., 2005. Public veterinary medicine: public health - rabies surveillance in the United States during 2004. Journal of the American Veterinary Medical Association 227, 1912-1925.

Kriendel, S.M., McGill, M., Meltzer, M.I., Rupprecht, C.E., DeMaria, A.J., 1998. The cost of rabies postexposure prophylaxis: one state's experience. Public Health Reports 113, 247-251.

Kuzmin, I.V., Hughes, G.J., Botvinkin, A.D., Orciari, L.A., Rupprecht, C.E., 2005. Phylogenetic relationships of Irkut and West Caucasian bat viruses within the Lyssavirus genus and suggested quantitative criteria based on the $\mathrm{N}$ gene sequence for lyssavirus genotype definition. Virus Research 111, 2843.

Loomis, J., Gonzalez-Caban, A., 1998. A willingness-to-pay function for protecting acres of spotted owl habitat from fire. Ecological Economics 25, 315-322.

Macdonald, D.W., 1980. Rabies and Wildlife: A Biologist's Perspective. Oxford University Press, Oxford. p. 151.

Macdonald, D.W., 1993. Rabies and wildlife: a conservation problem? Onderstepoort. Journal of Veterinary Research 60, 351-355.
Macdonald, D.W., Voigt, D.R., 1985. The biological basis of rabies models. In: Bacon, P.J. (Ed.), Population Dynamics of Rabies in Wildlife. Academic Press, London, pp. 71-108.

Macdonald, D.W., Courtenay, O., Forbes, S., Mathews, F., 1999. The red fox (Vulpes vulpes) in Saudi Arabia: loose-knit groupings in the absence of territoriality. Journal of Zoology, London 249, 383-391.

MacInnes, C.D., Smith, S.M., Tinline, R.R., Ayers, N.R., Bachmann, P., Ball, D.G.A., Calder, L.A., Crosgrey, S.J., Fielding, C., Hauschildt, C.P., Honig, J.M., Johnston, D.H., Lawson, K.F., Nunan, C.P., Pedde, M.A., Pond, B., Stewart, R.B., Voigt, D.R., 2001. Elimination of rabies from red foxes in Eastern Ontario. Journal of Wildlife Diseases 37, 119-132.

MacKenzie, D., 2005. Rabies cases spark emergency action. New Scientist, 2. Available from <http://www.newscientist.com/ article/mg18624934800.html>.

Marks, C.A., Bloomfield, T.E., 1999. Distribution and density estimates for urban foxes (Vulpes vulpes) in Melbourne: implications for rabies control. Wildlife Research 26, 763-775.

McCallum, H., Barlow, N., Hone, J., 2001. How should pathogen transmission be modelled? Trends in Ecology and Evolution 16, 295-300.

Meltzer, M.I., 1996. Assessing the costs and benefits of an oral vaccine for raccoon rabies: a possible model. Emerging Infectious Diseases 2, 343-349.

Meltzer, M.I., Rupprecht, C.E., 1998a. A review of the economics of the prevention and control of rabies part 1: global impact and rabies in humans. Pharmacoeconomics 14, 366-383.

Meltzer, M.I., Rupprecht, C.E., 1998b. A review of the economics of the prevention and control of rabies part 2: rabies in dogs, livestock and wildlife. Pharmacoeconomics 14, 481-498.

Meslin, F.X.D., Fishben, D.B., Matter, H.C., 1994. Rationale and prospects for rabies elimination in developing countries. Current Topics in Microbiology and Immunology 187, 1-26.

Miller, L.A., Johns, B.E., Elias, D.E., 1998. Immunocontraception as a wildlife management tool: some perspectives. Wildlife Society Bulletin 26, 237-243.

Müller, J., 1966. The reappearance of rabies in Denmark. Bulletin l'Office International des Épizooties 65, 21-29.

Nadin-Davis, S.A., Huang, W., Armstrong, J., Casey, G.A., Bahloul, C., Tordo, N., Wandeler, A.I., 2001. Antigenic and genetic divergence of rabies viruses from bat species indigenous to Canada. Virus Research 74, 139-156.

Nagy, A., Kerekes, B., Heltay, I., 1995. Oral immunization of foxes (wildlife carnivores) - results in Hungary. Magyar Allatorvosok Lapja 50, 95-100.

National Association of State Public Health Veterinarians Committee, 2004. Compendium of animal rabies prevention and control, 2004. Journal of the American Veterinary Medical Association 224 (2), 216-221.

Niezgoda, M., Hanlon, C.A., Rupprecht, C.E., 2002. Animal rabies. In: Jackson, A.C., Wunner, W.H. (Eds.), Rabies. Academic Press, Boston, pp. 163-218.

Noah, D.L., Smith, M.G., Gotthardt, J.C., Krebs, J.W., Green, D., Childs, J.E., 1996. Mass human exposure to rabies in New Hampshire: exposures, treatment and cost. American Journal of Public Health 86, 1149-1151.

Normand, S.L.T., McNeil, B.J., Peterson, L.E., Palmer, R.H., 1998. Methodology matters - VIII - eliciting expert opinion using the Delphi technique: identifying performance indicators for cardiovascular disease. International Journal for Quality in Health Care 10, 247-260.

Nunan, C.P., Tinline, R.R., Honig, J.M., Ball, D.G.A., Hausefield, P., LeBer, C.A., 2002. Postexposure treatment and animal rabies, Ontario, 1958-2000. Emerging Infectious Diseases 8 (2), 217.

Ortega, N.R.S., Sallum, P.C., Massad, E., 2000. Fuzzy dynamical systems in epidemic modelling. Kybernetes 29, 201-218. 
Ortega, N., Barros, L.C., Massad, E., 2003. Fuzzy gradual rules in epidemiology. Kybernetes 32, 460-477.

Ostfeld, R.S., Glass, G.E., Keesing, F., 2005. Spatial epidemiology: an emerging (or re-emerging) discipline. Trends in Ecology and Evolution 20, 328-336.

Parker, R.L., Wilsnack, R.E., 1966. Pathogenesis of skunk rabies virus: quantification in skunks and foxes. American Journal of Veterinary Research 27, 33-38.

Ramsey, D., Spencer, N., Caley, P., Efford, M., Hansen, K., Lam, M., Cooper, D., 2002. The effects of reducing population density on contact rates between brushtail possums: implications for transmission of bovine tuberculosis. Journal of Applied Ecology 39, 806-818.

Randall, D.A., Williams, S.D., Kuzmin, I.V., Rupprecht, C.E., Tallents, L.A., Tefera, Z., Argaw, K., Shiferaw, F., Knobel, D.L., Sillero-Zubiri, C., Laurenson, M.K., 2004. Rabies in endangered Ethiopian wolves. Emerging Infectious Diseases 10 [available online http://www.cdc.gov/ncidod/eid/vol10no12/pdfs/040080.pdf].

Randall, D.A., Marino, D.T., Sillero-Zubiri, C., Knobel, D.L., Tallents, L.A., Macdonald, D.W., Laurenson, M.K., 2006. Integrated disease management for the control of rabies in Ethiopian wolves. In: Macdonald, D.W., Laurenson, K. (Eds.), Infectious Disease and Mammalian Conservation. Biological Conservation 131 (2), 151-162.

Rosatte, R., Donovan, D., Allan, M., Howes, L.A., Silver, A., Bennett, K., MacInnes, C., Davies, C., Wandeler, A., Radford, B., 2001. Emergency response to raccoon rabies introduction into Ontario. Journal of Wildlife Diseases 37 (2), 265-279.

Russell, C.A., Smith, D.L., Childs, J.E., Real, L.A., 2005. Predictive spatial dynamics and strategic planning for raccoon rabies emergence in Ohio. PLoS Biology 3 (3), 382-388.

Schaefer, R., Batista, H.B.R., Franco, A.C., Rijsewijk, F.A.M., Roehe, P.M., 2005. Studies on antigenic and genomic properties of Brazilian rabies virus isolates. Veterinary Microbiology 107, 161-170.

Shwiff, S.A., Sterner, R.T., Jay-Russell, M.T., Parikh, S., Bellomy, A., Meltzer, M.I., Rupprecht, C.E., Slate, D., submitted for publication. Direct and indirect costs of rabies exposure: a retrospective study in southern California. Journal of Wildlife Diseases.

Sidwa, T.J., Wilson, P.J., Moore, G.M., Oertli, E.H., Hicks, B.N., Rohde, R.E., Johnston, D.H., 2005. Evaluation of oral rabies vaccination programs for control of rabies epizootics in coyotes and gray foxes: 1995-2003. Journal of the American Veterinary Medical Association 227, 785-792.

Slate, D., Chipman, R.E., Rupprecht, C.E., Deliberto, T., 2002. Oral rabies vaccination: a national perspective on program development and implementation. Proceedings of the Vertebrate Pest Conference 20, 232-240.

Slate, D., Rupprecht, C.E., Rooney, J.A., Donovan, D., Lein, D.H., Chipman, R.B., 2005. Status of oral rabies vaccination in wild carnivores in the United States. Virus Research 111, 68-76.

Smith, G.C., 1995. Modelling rabies control in the UK: the inclusion of vaccination. Mammalia 59, 629-637.

Smith, G.C., 2001. Models of Mycobacterium bovis in wildlife and cattle. Tuberculosis 81, 51-64.

Smith, G.C., 2002a. The role of the badger (Meles meles) in rabies epizootiology and the implications for Great Britain. Mammal Review 32, 13-26.

Smith, J.S., 2002b. Molecular epidemiology. In: Jackson, A.C., Wunner, W.H. (Eds.), Rabies. Academic Press, Boston, pp. 79-111.

Smith, G.C., 2005. Modelling bovine tuberculosis in wildlife and cattle. In: Smithe, L.T. (Ed.), Progress in Tuberculosis Research. Nova Science, New York, pp. 249-280.
Smith, G.C., in press. Persistence of disease in territorial animals: insights from a model of $\mathrm{Tb}$ control in badgers. New Zealand. Journal of Ecology.

Smith, G.C., Cheeseman, C.L., 2002. The control of diseases in wildlife populations: culling, vaccine and fertility control. Ecological Modelling 150, 45-53.

Smith, G.C., Fooks, A.R., 2006. Wildlife rabies control policy in Great Britain. Developments in Biologicals 125, 113-118.

Smith, G.C., Harris, S., 1989. The control of rabies in urban fox populations. In: Putman, R.J. (Ed.), Mammals as Pests. Chapman and Hall, London, pp. 209-224.

Smith, G.C., Wilkinson, D., 2003. Modelling control of rabies outbreaks in red fox populations to evaluate culling, vaccination, and vaccination combined with fertility control. Journal of Wildlife Diseases 39, 278-286.

Sterner, R.T., Sun, B., 2004. Relative factor costs of wildlife rabies impacts in the US. Proceedings of the Vertebrate Pest Conference 21, 185-189.

Sterner, R.T., Kling, M.M., Shwiff, S.A., Slate, D., 2004. Oral rabies vaccination: reducing economic uncertainty via response surface analysis. Proceedings of the Wildlife Damage Management Conference 10, 134-145.

Stöhr, K., Meslin, F.M., 1996. Progress and setbacks in the oral immunisation of foxes against rabies in Europe. Veterinary Record 139, 32-35.

Tischendorf, L., Thulke, H.-H., Staubach, C., Jelsch, F., Goretzki, J., Selhorst, T., Schluter, H., Wissel, C., 1998. Chance and risk of controlling rabies in large-scale and long-term immunized fox populations. Proceedings of the Royal Society of London B 265, 839-846.

Uhaa, I.J., Data, V.M., Sorhage, F.E., Beckley, J.W., Roscoe, D.E., Gorsky, R.D., Fishbein, D.B., 1992. Benefits and costs of using an orally absorbed vaccine to control rabies in raccoons. Journal of the American Veterinary Medical Association 201, 1873-1882.

United States Department of Agriculture, 1994. Animal Damage Control Program: Final Environmental Impact Statement, vols. 1-3. Animal and Plant Health Inspection Service, Wildlife Services, Washington, DC.

United States Department of Agriculture, 2001. Wildlife Rabies Control Plan. Animal and Plant Health Inspection Service, Wildlife Services, Riverdale, Maryland. 30 pp.

Van der Straaten, J., 2002. Challenges and pitfalls of cost-benefit analysis in environmental issues. In: Puttaswamiah, K. (Ed.), Cost-benefit Analysis: Environmental and Ecological Perspectives. Transaction Publishers, London, pp. 322-346.

Voight, D.R., Tinline, R.R., 1982. Fox rabies and trappings: a study of disease and fur harvest interaction. In: Sanderson, G.C. (Ed.), Midwest furbearer management, Proceedings of the symposium held at the 43rd Midwest Wildlife Conference. The Wildlife Society, Washington, DC, pp. 119-132.

Wandeler, A.I., 2000. Oral immunization against rabies: afterthoughts and foresight. Schweizer Archiv für Tierheilkunde 142, 455-462.

Westergaard, J.M., 1982. Measures applied in Denmark to control the rabies epizootic in 1977-1980. Comparative Immunology, Microbiology and Infectious Diseases 5, 383-387.

White, P.C.L., Harris, S., 1994. Encounters between red foxes (Vulpes vulpes): implications for territory maintenance, social cohesion and dispersal. Journal of Animal Ecology 63, 315-327.

White, G.C., Lubow, B.C., 2002. Fitting population models to multiple sources of observed data. Journal of Wildlife Management 66, 300-309.

WHO, 1992. Expert Committee on Rabies, eighth Report. WHO, Geneva.

Woodroffe, R., Donnelly, C.A., Cox, D.R., Bourne, F.J., Cheeseman, C.L., Delahay, R.J., Gettinby, G., McInerney, J.P., Morrison, W.I., 
2006. Effects of culling on badger Meles meles spatial organization: implications for the control of bovine tuberculosis. Journal of Applied Ecology 43, 1-10.

Wunner, W.H., 2002. Rabies virus. In: Rabies Jackson, A.C., Wunner, W.H. (Eds.), Rabies. Academic Press, San Diego, pp. 23-77.
Zanoni, R.G., Kappeler, A., Muller, U.M., Muller, C., Wandelier, A.I., Breitenmoser, U., 2000. Rabies-free status of Switzerland following 30 years of rabies in foxes. Schweizer Archiv für Tierheilkunde 142, 423-429.

Zerbe, R.O., Dively, D.D., 1994. Benefit-cost Analysis in Theory and Practice. HarperCollins College Publishers, New York. 